\title{
Epstein-Barr virus inactivates the transcriptome and disrupts the chromatin architecture of its host cell in the first phase of lytic reactivation
}

\author{
Alexander Buschle ${ }^{1}$, Paulina Mrozek-Gorska ${ }^{1}$, Stefan $\mathrm{Krebs}^{2}$, Helmut Blum², Filippo M. \\ Cernilogar ${ }^{3}$, Gunnar Schotta ${ }^{3}$, Dagmar Pich ${ }^{1}$, Tobias Straub ${ }^{3}$, and Wolfgang \\ Hammerschmidt $^{1 *}$ \\ ${ }^{1}$ Research Unit Gene Vectors \\ Helmholtz Zentrum München \\ German Research Center for Environmental Health and \\ German Center for Infection Research (DZIF), Partner site Munich, Germany \\ Marchioninistr. 25 \\ D-81377 Munich, Germany \\ ${ }^{2}$ Laboratory for Functional Genome Analysis (LAFUGA), Gene Center of the Ludwig- \\ Maximilians-Universität (LMU) München, Munich, Germany \\ ${ }^{3}$ Biomedical Center, Molecular, Biology, LMU Munich, 82152 Planegg-Martinsried, Germany
}

*To whom correspondence should be addressed.

Tel: +49 893187 1506;

Fax: +49 893187 4225;

Email: hammerschmidt@helmholtz-muenchen.de 


\begin{abstract}
Epstein-Barr virus (EBV), a herpes virus also termed HHV 4 and the first identified human tumor virus, establishes a stable long-term latent infection in human B cells, its preferred host. Upon induction of EBV's lytic phase the latently infected cells turn into a virus factory, a process, that is governed by EBV. In the lytic, productive phase all herpesviruses ensure the efficient induction of all lytic viral genes to produce progeny, but certain of these genes also repress the ensuing antiviral responses of the virally infected host cells, regulate their apoptotic death or control the cellular transcriptome. We now find that EBV causes previously unknown massive and global alterations in the chromatin of its host cell upon induction of the viral lytic phase and prior to the onset of viral DNA replication. The viral initiator protein of the lytic cycle, BZLF1, binds to $>10^{5}$ binding sites with different sequence motifs in cellular chromatin and in a concentration dependent manner. Concomitant with DNA binding, silent chromatin opens locally as shown by ATAC-seq experiments, while previously wide-open cellular chromatin becomes inaccessible on a global scale within hours. While viral transcripts increase drastically, the induction of the lytic phase results in a massive reduction of cellular transcripts and a loss of chromatin-chromatin interactions of cellular promoters with their distal regulatory elements as shown in Capture-C experiments. Our data document that EBV's lytic cycle induces discrete early processes that disrupt the architecture of host cellular chromatin and repress the cellular epigenome and transcriptome likely supporting the efficient de novo synthesis of this herpesvirus.
\end{abstract}




\section{INTRODUCTION}

Viruses exploit their hosts at the cellular or organismic level to support viral propagation and spread. Towards this end they also manipulate the infected cellular host with their own toolkit to suppress various antiviral defense mechanisms. For example, viruses can inhibit several levels of interferon responses (Qian et al., 2017 and references therein), they counteract cellular cytidine deaminases with potent antiviral activities (Zheng et al., 2012), reduce cellular immunity with viral micro RNAs (Albanese et al., 2017), or even mimic histone tails to interfere with antiviral responses of the infected cells (Marazzi et al., 2012).

The manipulation of the host's antiviral programs is especially important for herpes viruses. Commonly, they turn the infected cell into a virus factory, but they can also initiate their temporal coexistence in certain cells to establish long-lasting, non-productive, latent infections. During latency, the herpesviral genomic DNA acquires a genuine cellular and highly repressive chromatin signature, which blocks transcription of most viral genes. Herpes viruses can escape from the latent phase and reactivate virus production. In this step, herpes viruses instruct their cellular host to remove the repressive epigenetic signature from viral chromatin to allow and activate massive viral transcription of all lytic viral genes within hours. During lytic reactivation, the host cell must also be manipulated to provide chemical energy, macromolecules, and nuclear space for the so-called viral replication compartments (Quinlan et al., 1984; Monier et al., 2000) or amplification factories (Chiu et al., 2013). Additionally, the cell's transcription machinery needs to be redirected to support an efficient virus de novo transcription within a few hours after reactivation. Many molecular details of these fundamental processes are unknown.

A ubiquitous human herpes virus is Epstein-Barr virus (EBV, HHV4), which infects about $95 \%$ of the human population. B lymphocytes are the preferred target cells in which EBV establishes a latent infection initially. EBV reactivates from this latent state with the help of the viral BZLF1 protein, which is expressed upon differentiation of EBV-infected memory $B$ cells to plasma cells (Laichalk and Thorley-Lawson, 2005) and induces the switch from latency to EBV's lytic phase (Countryman and Miller, 1985; Takada et al., 1986). BZLF1, which is also called EB1, ZEBRA, zta, or Z, is known to act as an essential viral transcription and replication factor (Takada et al., 1986; Countryman and Miller, 1985; Schepers et al., 1993). BZLF1 binds two classes of DNA binding motifs (ZREs) in the viral genome, one of which needs to be methylated to be bound efficiently (Bergbauer et al., 2010; Bhende et al., 2004). These sites are termed CpG-ZREs or meZREs and are mainly positioned in promoters of important lytic viral genes (Bergbauer et al., 2010; Kalla et al., 2010). Upon initial infection during EBV's pre-latent phase (Jochum et al., 2012), BZLF1 is transiently 
expressed (Wen et al., 2007; Kalla et al., 2010), but it does not bind its many viral CpGZREs, because the incoming viral DNA is free of methylated CpG dinucleotides (Kalla et al., 2012). As a consequence, the virus cannot activate its lytic promoters in the pre-latent phase but it rather initiates its latent program, which leads to the restricted expression of the few latent viral genes, only. CpG methylation of viral DNA is a slow process in newly infected primary B cells that takes several weeks to completion (Woellmer et al., 2012), but CpG methylation further supports the epigenetic silencing of all viral lytic genes (Kenney and Mertz, 2014). It is likely that EBV uses this strategy to prevent the premature expression of its lytic genes in newly infected cells, which would induce a massive antiviral immune response of EBV-specific $T$ cells and would readily eliminate the virally infected cells (Kalla and Hammerschmidt, 2012).

BZLF1 is a homo-dimeric bZIP transcription factor. Its DNA binding domain shows a strong homology to the cellular AP-1 protein family including the Jun, Fos, Fra, and ATF subfamilies. AP-1 binding motifs and ZREs are related sequences of about seven nucleotides (Lieberman et al., 1990; Chang et al., 1990). Similar to BZLF1, C-Jun/c-Fos heterodimers can also bind to and regulate cellular genes via methylated DNA motifs, which are related to CpG-ZRE motifs of BZLF1 (Gustems et al., 2014). Collectively, these findings suggest that BZLF1 may widely influence cellular transcription since several hundred thousand motifs of members of the AP-1 family are known in the genome of mammalian cells (Zhou et al., 2005), some of which are located in enhancers (Lee et al., 1987; Chavanas et al., 2008; Zanconato et al., 2015; Phanstiel et al., 2017; Vierbuchen et al., 2017). AP-1 family members participate in regulating genes involved in cellular proliferation, differentiation, and apoptosis (Shaulian and Karin, 2001; Shaulian and Karin, 2002; Ameyar et al., 2003; Eferl and Wagner, 2003), pathways which EBV also manipulates in its pre-latent, latent and lytic phases.

Much is known about the impact of BZLF1 on the viral genome after induction of EBV's lytic phase and the ensuing alterations in viral chromatin (Schaeffner et al., 2019; Woellmer et al., 2012), but if and how herpesviruses in general and EBV in particular manipulate the chromatin of the host cell during the early hours of lytic, productive infection is not known in detail. Therefore, we examined the global modification of the host genome in the lytic, prereplicative phase of EBV. We chose the Raji cell line as our preferred model for two reasons: (i) in Raji cells, EBV's latent phase is very tightly controlled, but, upon induction the majority of the cells readily enter EBV's lytic phase. The lytic phase, however, is incomplete and does not support the amplification the viral DNA because Raji cells carry a defective EBV genome (Polack et al., 1984; Hatfull et al., 1988; Decaussin et al., 1995).Thus, Raji cells (ii) allow studying the very early modifications in cellular chromatin in the pre-replicative phase when 
the cells transit from viral latency to lytic reactivation but prior to the formation of replication compartments or amplification factories. In EBV-infected cells they become microscopically visible as early as 16 to 24 hours after lytic phase induction and are characterized by the local accumulation of EBV DNA and the occlusion of cellular chromatin constituents such as histones (Chiu et al., 2013). This report also indicated that the nuclear architecture of the lytically induced cells undergoes substantial modifications prior to the formation of the amplification factories, because the nuclei show an initial 'honeycombed' structure suggestive of an early reorganization of the cellular chromatin or nuclear 3D architecture.

BZLF1 and certain members of cellular transcription factor family AP-1 are structurally and functionally similar. It seems therefore plausible that BZLF1 may take part in manipulating the chromatin and transcriptome of its cellular host during viral reactivation and the subsequent lytic phase. While our focus was on detecting global changes within the host cell upon induction of the lytic cycle we also considered the possible role of BZLF1 in inducing modifications in the host cell with respect to the cell's transcriptome, chromatin accessibility, and chromatin-chromatin interactions.

We discovered that the induction of EBV's lytic phase induces global alterations in the host cell chromatin. We found (i) a massive reduction of cellular transcripts indicative of the virus-induced host shut-off, (ii) a prevalent reduction or even collapse of chromatinchromatin interactions concomitant with a (iii) general loss of chromatin accessibility, and (iv) a localized opening of chromatin at the majority of about $10^{5}$ cellular BZLF1 binding sites. These findings document that the host cell is subject to global nuclear changes already in the pre-replicative phase of the virus' lytic cycle.

\section{MATERIAL AND METHODS}

\section{Eukaryotic cell lines}

The cell lines B95-8 (EBV-positive) (Miller and Lipman, 1973), DG75 (EBV-negative) (Ben-Bassat et al., 1977), and Raji (EBV-positive) (Pulvertaft, 1964) and their derivatives were cultured in RPMI 1640 medium (Life Technologies) supplemented with $1 \mathrm{mM}$ sodium pyruvate (Life Technologies), $100 \mu \mathrm{g} / \mathrm{ml}$ streptomycin, $100 \mathrm{units} / \mathrm{ml}$ penicillin (Life Technologies), and $8 \%$ fetal bovine serum (FBS) (BioSell) in an atmosphere with $5 \% \mathrm{CO}_{2}$, $95 \%$ humidity at $37^{\circ} \mathrm{C} .1 \mathrm{mg} / \mathrm{ml}$ puromycin (Invitrogen) was added to the cells to select for the maintenance of oriP plasmids with two conditional doxycycline inducible BZLF1 alleles: iBZLF1 (p4816) and iBZLF1 (p5694) encode the wild-type BZLF1 and the activation domain 
(AD)-truncated alleles, respectively. On average, the cells were kept at a density of $5 \times 10^{5}$ cells/ml. HEK 293 cells (Graham et al., 1977) were kept at a confluency of about $70 \%$. HEK 293 cells that produce the EBV strain wt/B95.8 (2089) upon induction were cultivated with $100 \mathrm{ng} / \mathrm{ml}$ hygromycin as described (Delecluse et al., 1998).

\section{Plasmids}

The doxycycline inducible BZLF1 expressing plasmids p4816 and p5694, which encode full-length iBZLF1 and the activation domain (AD)-truncated iBZLF1, respectively, are described in Woellmer et al. (Woellmer et al., 2012). The two plasmids also express the green fluorescent protein (GFP) upon doxycycline addition (Bornkamm et al., 2005). The BZLF1 plasmid p5406 expresses full-length BZLF1 with an amino-terminal tandem step-tag as described (Schäffner, 2015).

\section{Quantitative BZLF1 expression analysis}

BZLF1 protein was purified from HEK 293 cells transiently transfected with the BZLF1step-tag expressing plasmid p5406 for 48 h. Cells were lysed in RIPA buffer ( $1 \%$ NP-40, $0.1 \%$ SDS, $0.5 \%$ sodium deoxycholate, $150 \mathrm{mM} \mathrm{NaCl}, 50 \mathrm{mM}$ Tris- $\mathrm{HCl} \mathrm{pH}$ 8.0, $1 \mathrm{x}$ proteinase inhibitor cocktail (Roche)), incubated (20 min), and sheared on ice with a Branson sonifier 250-D (10 sec on/ $50 \mathrm{sec}$ off, $1 \mathrm{~min}, 20 \%$ amplitude). The lysates were centrifuged (15 min, $16,000 \mathrm{~g}, 4^{\circ} \mathrm{C}$ ) and the supernatants were purified with IBA Strep-Tactin sepharose beads (IBA, 2-1201-002) on Poly-Prep Chromatography Columns (731-1550, BioRad) with IBA's buffer's W (washing) and $E$ (elution). The concentration of purified protein was determined by Coomassie staining of $14 \%$ gels after SDS-PAGE with BSA standards obtained from the Pierce BCA protein assay kit (23209, Thermo Fisher Scientific). The purified BZLF1 protein was used as a quantitative standard and reference for subsequent Western blot analyses.

For BZLF1 expression level analysis $2.5 \times 10^{6}$ DG75, B95-8 cells, non-induced Raji iBZLF1 cells, or Raji iBZLF1 cells induced for $6 \mathrm{~h}$ were lysed in RIPA buffer and sheared with the BioRuptor (Diagenode) four times ( $5 \mathrm{~min}, 30 \mathrm{on} / \mathrm{off}$, high) in ice cold water. $5 x$ Laemmli loading buffer containing $15 \%$ DTT $(1 \mathrm{M})$ and $0.75 \%$ beta-mercaptoethanol were added to the lysates. Aliquots of these lysates corresponding to different cell numbers were loaded onto $14 \%$ SDS-PAGE gels and analyzed by Western blot immune detection. BZLF1 was detected with the BZ1 antibody (Young et al., 1991), which was used at a 1:50 dilution in combination with a secondary anti-mouse HRP antibody (1:10,000, Cell Signaling \#7076S). ECL Select (GE Healthcare) was used for signal detection, which were quantified with a 
Fusion FX (VILBER) system. Calculation and visualization of BZLF1 dimers was done with $\mathrm{R}$ (Team, 2018).

\section{Intracellular BZLF1 staining}

For the intracellular staining of BZLF1 Fix \& Perm permeabilization Kit (Invitrogen) was used. $1 \times 10^{6}$ cells were centrifuged (300 g, $10 \mathrm{~min}$ ) and washed with $100 \mu \mathrm{l}$ PBS. $100 \mu \mathrm{l}$ of Kit reagent $A$ were added (15 min, in the dark). Samples were washed with $2 \mathrm{ml}$ wash buffer (PBS, $50 \%$ FBS, $0.1 \% \mathrm{NaN}_{3}$ ) before $100 \mu \mathrm{l}$ Kit reagent B was added. $1 \mu \mathrm{l} \mathrm{BZ1}$ antibody coupled with Alexa647 was added before vortexing $(2 \mathrm{sec}$ ) and incubation (20 min, RT, in the dark). Samples were washed with $2 \mathrm{ml}$ wash buffer and taken up in $0.5 \mathrm{ml}$ wash buffer afterwards for FACS analysis (BD Fortessa).

\section{Virus titration}

The 2089.2.22.7 version of HEK 293 cells stably transduced with the maxi-EBV plasmid p2089 releases the EBV strain wt/B95.8 (2089) upon BZLF1 expression (Delecluse et al., 1998). This cell line was transfected with the inducible iBZLF1 expression plasmid p4816

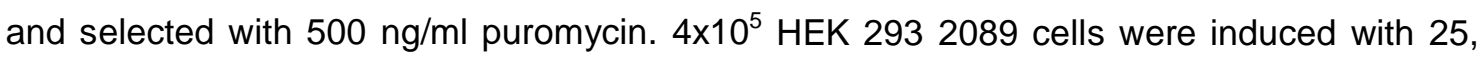
100 , or $200 \mathrm{ng}$ doxycycline/ml for three days or the cells were left uninduced as a control. The supernatants were filtered through a filter with a pore size of $1.2 \mu \mathrm{m}$ and 25,50 , or 100 $\mu$ l were used to infect $10^{5}$ parental Raji cells. GFP positive Raji cells (Green Raji units) were identified via FACS analysis as described in detail (Steinbrück et al., 2015). The virus concentrations were calculated and visualized with $\mathrm{R}$.

\section{Next generation ChIP-sequencing}

For immunoprecipitation two samples with $1 \times 10^{8}$ cells each were adjusted to a concentration of $5 \times 10^{5} \mathrm{cells} / \mathrm{ml}$ in fresh medium and were left non-induced or were induced with a final concentration of $100 \mathrm{ng} / \mathrm{ml}$ doxycycline (Sigma-Aldrich) for $15 \mathrm{~h}$. Nuclei were extracted with hypotonic buffer $(10 \mathrm{mM} \mathrm{KCl}, 340 \mathrm{mM}$ Sucrose, $1.5 \mathrm{mM} \mathrm{MgCl}$, $10 \mathrm{mM}$ Hepes pH 7.9) containing $10 \%$ proteinase inhibitor cocktail (PIC, Roche) and lysed in RIPA buffer $+1 \mathrm{x}$ PIC. The chromatin was shared in a BioRuptor on wet ice (4 cycles, 5 min each, 30 on/off, high). The chromatin was immunoprecipitated with the BZ1 antibody (Young et al., 1991), $10 \%$ input was used as a control. The precipitates were washed with different salt concentrations and the proteins were digested with proteinase K. For Raji cells, the library preparations and sequencing (Illumina, paired-end, $150 \mathrm{nt}$ ) were performed by Vertis Biotechnology AG (Freising, Germany). The results were mapped with bowtie2 2.2.6 (Langmead and Salzberg, 2012), formats were transformed with samtools 1.0 (Li et al., 2009) 
and bedtools v2.25.0 (Quinlan and Hall, 2010) and the peak calling of the samples versus input was done by MACS2 2.1.0 (Feng et al., 2012; Zhang et al., 2008). The overlapping peaks of two replicates were merged with bedtools intersect and the DREME algorithm (Bailey, 2011) and the MEME-Chip 4.10.1 suit (Bailey et al., 2015) were used for motif identification. Raji $15 \mathrm{~h}$ DREME motifs (Fig. 2A) were merged artificially. The original, individual motifs and sub-motifs are shown in Supplementary Figure S3B.

\section{ATAC-sequencing}

$10^{6}$ Raji cells with either inducible BZLF1 plasmid (iBZLF1, 4816) or AD-truncated BZLF1 (5694) were treated with $100 \mathrm{ng} / \mathrm{ml}$ doxycycline for $15 \mathrm{~h}$ or left untreated. The cells were FACS sorted for living cells (untreated) and living, induced cells (15 h induced), controlled with trypan blue, and prepared for NGS. Omni-ATAC was performed as previously described (Corces et al., 2017) with minor modifications. Briefly, 50,000 FACS sorted cells were washed in PBS, resuspended in $50 \mu$ of ATAC-seq resuspension buffer (RSB: $10 \square \mathrm{mM}$ Tris$\mathrm{HCl}, \mathrm{pH} 7.4,10 \square \mathrm{mM} \mathrm{NaCl}$, and $3 \square \mathrm{mM} \mathrm{MgCl}_{2}$ ) containing $0.1 \% \mathrm{NP} 40,0.1 \%$ Tween-20 and $0.01 \%$ digitonin (Promega) and were incubated on ice for $3 \square \mathrm{min}$. Following lysis, $1 \square \mathrm{ml}$ of ATAC-seq RSB containing $0.1 \%$ Tween-20 was added, and nuclei were collected at $500 \mathrm{~g}$ $\left(4{ }^{\circ} \mathrm{C}, 10 \square \mathrm{min}\right)$. Pelleted nuclei were resuspended in $50 \square \mu \mathrm{l}$ of transposition mix $(25 \square \mu \mathrm{l}$ $2 \square \mathrm{x} \square$ TD buffer, $2.5 \square \mu l$ Tagment DNA enzyme (Illumina Nextera DNA Library Preparation

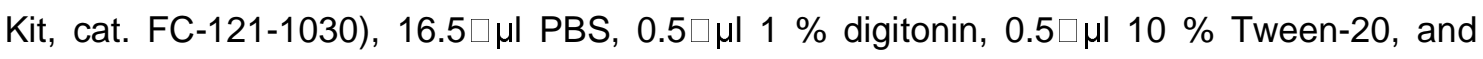
$5.25 \square \mu$ l water) and incubated at $37 \square{ }^{\circ} \mathrm{C}$ for $30 \square \mathrm{min}$ in a thermomixer shaking at $1,000 \mathrm{rpm}$. DNA was purified using Qiagen PCR clean-up MinElute kit (Qiagen). The transposed DNA was subsequently amplified in $50 \mu$ reactions with custom primers as described (Buenrostro et al., 2013). After four cycles libraries were then monitored with qPCR: $5 \mu l$ PCR sample in a $15 \square \mu l$ reaction with the same primers. qPCR output was monitored for the $\triangle \mathrm{RN} ; 0.25 \Delta \mathrm{RN}$ cycle number was used to estimate the number of additional cycles of the PCR reaction needed for the remaining PCR samples. Amplified libraries were purified with the Qiagen PCR clean-up MinElute kit (Qiagen) and size selected for fragments less than $600 \mathrm{bp}$ using the Agencourt AMPure XP beads (Beckman Coulter). Libraries were quality controlled by Qubit and Agilent DNA Bioanalyzer analysis. High throughput sequencing was performed by the Laboratory for Functional Genome Analysis (LAFUGA) of the Ludwig-MaximilianUniversity, Munich on an Illumina Hi-Seq 1500 using $50 \square$ nt single-end reads.

The data were mapped on the hg19 genome with Bowtie 1.1.2. The HOMER 4.9 software was used to calculate tag directories. The data for the metaplots and heatmaps were calculated with HOMER's annotatePeaks.pl tool on data from three independent experiments and visualized with $\mathrm{R}$ (3.5.1) (Team, 2018). For heatmaps visualization the 
data.table (https://cran.r-project.org/web/packages/data.table/index.html) and superheat packages (Barter and Yu, 2017) were used.

\section{Next generation RNA-sequencing}

For RNA sequencing parental Raji cells and their derivates carrying the conditional expression plasmids encoding full-length iBZLF1 or AD-truncated iBZLF1 were employed. At an initial cell concentration of $5 \times 10^{5}$ cells $/ \mathrm{ml}$, a total of $2 \times 10^{7}$ non-induced cells or $4 \times 10^{7}$ cells induced with $100 \mathrm{ng} / \mathrm{ml}$ doxycycline for $6 \mathrm{~h}$ were analyzed. Doxycycline leads to the coexpression of BZLF1 and the truncated human NGF-receptor. To limit the analysis to BZLF1 expressing cells, only, we sorted NGF-R-positive cells with magnetic beads (MACS, Miltenyi Biotec) and the primary anti-NGF-R antibody (HB8737-1, IgG1) and a secondary anti-mouse IgG (1:10, Miltenyi Biotech) antibody. $7.5 \times 10^{5}$ cells were lysed in $1 \mathrm{ml}$ Trizol (Thermo Fisher Scientific), snap frozen in liquid nitrogen and stored at $-80^{\circ} \mathrm{C}$.

Prior to RNA isolation identical molar amounts of ERCC spike-in control RNAs (Ambion) were added to $3 \times 10^{5}$ non-induced or doxycycline induced Raji iBZLF1 (0h/6h) cells. The subsequent processes and steps were identical for all cells. RNA was extracted with the Direct-zol RNA MiniPrep Kit (Zymo Reseach). The RNA concentration and quality were controlled with Nanodrop (Thermo Fisher Scientific), Quibit (Thermo Fisher Scientific), and Bioanalyzer (Agilent), and the RNAs were treated with dsDNase (Thermo Fisher Scientific). The Encore Complete RNA-Seq Library System kit (NuGEN), which uses not-so-random hexamer primers for rRNA depletion, was used for library preparation. The samples were sequenced on an Illumina HiSeq 1500 instrument (100 nt, single-end reads).

For bioinformatic analysis the samples were mapped with Tophat2 (Kim et al., 2013) on a Galaxy server (Afgan et al., 2016) to the Hg19 genome, locally with HiSat2 2.0.1 to EBV-Raji (KF717093), and reads were assigned to annotated genes with HTSeq-count 0.6.1p1 (Anders et al., 2015). The counts were compared between induced ( $6 \mathrm{~h}$ ) and non-induced (0 h) cells with the R package DESeq2 1.12.3 (Love et al., 2014). Samples with added ERCC spike-in RNAs were normalized to these. The visualization was done with $\mathrm{R}$ including the packages 'Extrafont' 0.17 (Chang, 2014) and 'RColorBrewer' 1.1-2 (Neuwirth, 2014).

\section{Promoter analysis}

Bedtools intersect was used to identify peaks in the data sets, which are located within the promoters (- $1 \mathrm{~kb} /+5 \mathrm{~kb}$ relative to TSS (UCSC, RefSeq Genes, Hg19)) of regulated and non-regulated genes. $\mathrm{R}$ was used to remove duplicates, calculate and visualize the number 
of BZLF1 peaks or motifs within the promoters. Genes with fewer than 20 reads were excluded from the analysis.

\section{Capture-C}

For Capture-C analysis, $10^{7}$ uninduced Raji iBZLF1 cells or cells induced for different time periods (6 h, $15 \mathrm{~h}$ ) with $100 \mathrm{ng} / \mathrm{ml}$ doxycycline were used. Cells were washed (PBS), filtered for single cells, and fixed (1\% formaldehyde, $10 \%$ fetal bovine serum in PBS). The fixation was quenched on ice with $1 \mathrm{M}$ glycine before cells were homogenized two times with a $20 \mathrm{G}$ syringe in $3 \mathrm{C}$ lysis buffer (10 mM TrisHCl (pH 7.5), $10 \mathrm{mM} \mathrm{NaCl}, 0.2 \% \mathrm{NP}-40$ in ddH2O + PIC). Cells were washed and taken up in 1.2x CutSmart buffer (NEB). SDS was added to a concentration of $0.1 \%$ and the cells were incubated $\left(65{ }^{\circ} \mathrm{C}, 40 \mathrm{~min}\right)$ while shaking $(1,200$ rpm). Triton X-100 was added to a final concentration of $4 \%$ and the cells were incubated $\left(37^{\circ} \mathrm{C}, 1 \mathrm{~h}, 1,200 \mathrm{rpm}\right)$. The cell suspension was divided into six aliquots of $200 \mu \mathrm{l}$ each and incubated with 80 units Dpnll at $37^{\circ} \mathrm{C}$ while shaking $(1,200 \mathrm{rpm})$ overnight followed by another 400 units of Dpnll for $4 \mathrm{~h}$. The reaction was stopped with SDS at a final concentration of $0.1 \%$. Samples were joined and diluted with $1.25 \times 3 \mathrm{C}$ ligation buffer (62.5 $\mathrm{mM}$ Tris- $\mathrm{HCl}$ ( $\mathrm{pH} 7.5), 12.5 \mathrm{mM} \mathrm{MgCl}$, $1.25 \mathrm{mM} \mathrm{ATP,} 12.5 \mathrm{mM}$ DTT in $\mathrm{ddH}_{2} \mathrm{O}$ ) and Triton $\mathrm{X}-100\left(37^{\circ} \mathrm{C}, 1 \mathrm{~h}\right.$, shaking ever $\left.10 \mathrm{~min}\right)$ to a final volume of $1.5 \mathrm{ml} .100$ units T4 DNA Ligase (Affymetrix) was used for DNA fragment ligation $\left(16^{\circ} \mathrm{C}\right.$ for $4.5 \mathrm{~h}$ and RT for $45 \mathrm{~min}$ ) followed by proteinase $\mathrm{K}$ treatment at $65^{\circ} \mathrm{C}$ for $1 \mathrm{~h}$ to revert crosslinking. RNAs were degraded with RNase $A\left(300 \mu \mathrm{g}, 37^{\circ} \mathrm{C}, 1 \mathrm{~h}\right)$. DNA was extracted with organic solvents $(2 / 3 \mathrm{v} / \mathrm{v}$ phenolchloroform and 1/3 v/v butanol), precipitated (EtOH, $100 \%)$, washed (EtOH $70 \%)$, and rehydrated (TE buffer).

$1.5 \mu \mathrm{g}$ DNA was sheared with a Covaris M-series instrument (Covaris, peak incident power: 50 watts; duty factor $20 \%$; cycles/burst: 200 counts, duration $200 \mathrm{sec}$ ). Samples were cleaned with Agencourt AMPure beads (Beckman Coulter). The library preparation and sequence capture were done as described in the SureSelectXT2 Target Enrichment System for Illumina Paired-End Multiplexed Sequencing manual (Agilent, Version: E1, June 2015). The desired fragments were captured with Dynabeads (Thermo Fisher Scientific). Finally, the samples were sequenced on a HiSeq 1500 (Illumina, paired-end reads, $100 \mathrm{nt}$ read length).

Overlapping paired-end reads were joined using the flash tool (Magoc and Salzberg, 2011). The sequences were Dpnll digested in silico with the dpnll2E.pl script (kindly provided by James Davies, Oxford, UK) and mapped with Bowtie 1.1.0 (Langmead et al., 2009). The perl script dpngenome3_1.pl (kindly provided by James Davies, Oxford, UK) was used to digest the hg19 genome in silico with Dpnll. Interactions between distant DNA 
fragments were identified with the CCAnalyser2.pl script (kindly provided by James Davies, Oxford, UK). The data were averaged between triplicates, normalized by the total number of interactions for all captured fragments per time point, and visualized with R. Additionally, ChIP-seq and RNA-seq results were added to the visualization. 


\section{RESULTS}

The aim of this study was to investigate the alterations of the chromatin structure and the transcriptome of latently infected B cells when BZLF1 is expressed and EBV's lytic cycle starts. First, we determined the physiological levels of BZLF1 protein in cells that naturally support virus de novo synthesis. Next, we stably introduced two conditional oriP plasmids into Raji cells. The two plasmids express regulated levels of full-length BZLF1 or BZLF1 devoid of its transactivation domain upon addition of doxycycline. The established human $B$ cell line Raji is latently infected with EBV, does not support EBV's lytic phase spontaneously but enters it rapidly and synchronously upon the induced expression of full-length BZLF1. We used this cell line (and parental controls) throughout our studies and investigated the cells in their non-induced state and upon addition of doxycycline for up to 15 hours covering the pre-replicative lytic phase of reactivated EBV. Indistinguishable from full-length BZLF1, BZLF1 without its transactivation domain binds to its many cognate sequence motifs, but cells that express it do not enter EBV's lytic phase (Woellmer et al., 2012; Schaeffner et al., 2019). We therefore used Raji cells engineered to express the conditional AD-truncated BZLF1 for certain control experiments.

\section{Lytic viral gene expression requires high levels of BZLF1.}

When latently EBV infected memory B cells come in contact with their cognate antigens the viral BZLF1 gene is activated and virus synthesis is induced (Laichalk and ThorleyLawson, 2005). In vivo, only single memory B cells respond to this trigger, which makes it technically impossible to determine the protein levels of BZLF1 required to induce and/or support the lytic phase of EBV's life cycle in these cells. Therefore, we turned to the B95-8 cell line because a small fraction within its population spontaneously enters the lytic phase and releases infectious virions. We first determined this fraction of cells in the lytic cycle to be $2.8 \%$ on average by intracellular FACS staining with an Alexa 647 fluorophore coupled monoclonal antibody directed against BZLF1.

We then obtained whole cell protein lysates from a known number of B95-8 cells and compared the BZLF1 signal intensities by Western blot immunodetection with known molar amounts of a truncated BZLF1 protein that was recombinantly expressed in HEK 293 cells and purified to high homogeneity (Supplementary Figs. S1 and S2). We also engineered Raji cells to carry a conditional BZLF1 allele on the oriP-based p4816 plasmid (Woellmer et al., 2012), added doxycycline for 6 hours (Raji 6h iBZLF1), and applied protein lysates of noninduced Raji cells (Raji Oh iBZLF1) to load onto the same gel. Depending on the cell line and its state of induction protein equivalents that corresponded to different cell numbers were loaded and quantified. Supplementary Figure 1A provides three independent replicates. 
Based on these considerations, we estimated that each B95-8 cell that was found to express BZLF1 by intracellular FACS staining contained $1.3 \times 10^{6} \pm 0.2 \times 10^{6}$ BZLF1 dimers on average. BZLF1 levels in Raji cells induced for $6 \mathrm{~h}$ with doxycycline were about 3.5-fold higher (Supplementary Fig. 1B) while the population of non-induced Raji cells still expressed detectable levels of BZLF1 that were lower by a factor of about 42 (Supplementary Fig. 1A, B).

We were concerned that the conditional expression plasmid p4816 is leaky and might express steady state levels of BZLF1 even in the absence of doxycycline that are sufficient to induce EBV's lytic phase in latently infected cells. Since Raji cells are incapable of fully supporting de novo virus synthesis (Polack et al., 1984) we turned to a derivative of HEK 2932089 cells that releases the EBV strain wt/B95.8 (2089) upon BZLF1 expression (Delecluse et al., 1998). We stably introduced the p4816 plasmid into these cells (HEK 293 2089 iBZLF1) and evaluated the concentration of EBV virions in the cells' supernatant in the absence and presence of different concentrations of doxycycline (Supplementary Fig. 1C). The supernatants were used to infect Raji cells that turn GFP-positive upon infection with the EBV strain wt/B95.8 (2089). Virus amounts were expressed as Green Raji units (GRU) as described (Delecluse et al., 1998; Steinbrück et al., 2015). As expected, only HEK 2932089 iBZLF1 cells released infectious wt/B95.8 (2089) EBV in a dose-dependent fashion after adding increasing concentrations of doxycycline but not the parental HEK 2932089 cells (Supplementary Fig. 1C). Without doxycycline the supernatants of HEK 2932089 iBZLF1 cells contained very low numbers of virus similar to supernatants obtained from the parental HEK 2932089 cells (Supplementary Fig. 1C). In all subsequent experiments a doxycycline concentration of $100 \mathrm{ng} / \mathrm{ml}$ was used in cells with the conditional expression plasmid p4816 (iBZLF1) to reach BZLF1 levels comparable to lytically induced B95-8 cells (Supplementary Fig. 1A, B).

In RNA-seq experiments using our conditional Raji iBZLF1 cell model, we compared viral lytic genes prior to and after induction of BZLF1 to test how the expression of BZLF1 influences their expression. Before induction, lytic genes were expressed only at very low levels, while latent genes were strongly expressed (Supplementary Tab. S1). Upon adding doxycycline for 6 hours, Raji iBZLF1 cells readily expressed many viral genes that clearly mark the onset of EBV's lytic phase. Figure 1 shows the log2 fold differential expression of viral genes comparing non-induced and induced Raji iBZLF1 cells after ERCC spike-in normalization (see below for experimental details). Very few viral genes were downregulated such as EBNA1 and EBNA2 among others latent genes (Supplementary Tab. S1). Five of the six early lytic genes known to be essential for lytic amplification of viral DNA (Fixman et al., 1992) were upregulated 60 to more than 250-fold: BBLF3-BBLF2, BBLF4, BALF5, 
BMLF1-BSLF1, and BMRF1 (highlighted genes in Fig. 1). BALF2, which is the sixth gene on this list and know to be deleted in Raji EBV DNA (Decaussin et al., 1995). Additional genes that contribute to the lytic replication of viral DNA were strongly induced: BKRF3, BRLF1, BHLF1, and BMLF1 as well as BZLF1 (Fixman et al., 1995) (Fig. 1). The most strongly upregulated gene, BDLF3.5, was induced almost 300-fold. Supplementary Table S1 provides a list of viral genes and their regulation.

\section{BZLF1 binds a high number of DNA motifs in cellular chromatin}

The binding sites and sequence motifs of BZLF1 were already identified and further analyzed in the viral genome (Bergbauer et al., 2010; Dickerson et al., 2009; Flower et al., 2011). BZLF1 is a member of the cellular AP-1 family of transcription factors (Farrell et al., 1989), which are estimated to bind about 500,000 sites in human DNA (Zhou et al., 2005). We therefore hypothesized that BZLF1 might also bind to many accessible sites in the chromatin of human B cells. To address this possibility, we used our conditional iBZLF1 Raji cell model to identify BZLF1 binding sites in a genome-wide ChIP-seq approach.

We analyzed three different experimental conditions using the BZ1 monoclonal antibody directed against the dimerization domain of BZLF1 (Young et al., 1991) in our ChIP-seq analysis: Raji iBZLF1 cells in their (i) non-induced state and (ii) after induction of full-length BZLF1 with $100 \mathrm{ng} / \mathrm{ml}$ doxycycline for 15 hours, as well as (iii) DG75 cells free of EBV as a negative control.

In the control DG75 cells we found few mappable reads after ChIP-seq that rarely accumulated to peaks. This finding suggested that our ChIP-seq protocol delivers data with a very low background, because DG75 cells do not express BZLF1.

When BZLF1 is expressed at low levels in Raji iBZLF1 cells in the absence of doxycycline (Supplementary Fig. 1) we found about 30,000 ChIP peaks, of which $70 \%$ (Fig. 2A) contained the known BZLF1 binding motif TGWGCGA (Fig. 2C) also termed meZRE (Bergbauer et al., 2010; Woellmer et al., 2012). BZLF1 preferentially binds this motif when its CpG dinucleotide contains methylated 5'-cytosine residues (Bergbauer et al., 2010). When the cells were induced with doxycycline for 15 hours, more than half of the peaks with this motif were preserved (Fig. 2B), but the total number of peaks increased dramatically (Fig. 2A, B). Now, about 146,000 ChIP peaks were identified, of which $92 \%$ (Fig. 2A) contained one or more copies of the less precisely defined consensus motif TGWGYVA (Fig. 2C). At low BZLF1 levels this motif was not among the highly ranked motifs. Supplementary Figure S3 contains detailed information about different motif compositions, their frequencies and $p$ values comparing the non-induced and induced states in iBZLF1 Raji cells. 
In a minor fraction of called peaks the MEME-Chip suite (Bailey et al., 2015) failed to identify a common sequence motif for unknown reasons. We therefore turned to a visual inspection of the DNA sequences within the peak regions of this ChIP fraction. After inspection of peaks, in which no other motif could be identified previously, we found an additional and related sequence motif TGWGYVT. This motif is very similar to the meZRE motif TGWGYVA except its last nucleotide residue. We continued our analysis with a computational search for this possible motif in the sets of called ChIP peaks. Data shown in Supplementary Figure S4A indicate that $58 \%$ of all peaks in Raji iBZLF1 cells contained the motif TGWGYVT when BZLF1 levels were high (Supplementary Fig. S4A). Taking both motifs with terminal $\mathrm{A}$ or $\mathrm{T}$ residues into consideration, $96 \%$ of all peaks contained the consensus motif TGWGYVW at high BZLF1 levels. Detailed information about the motif can be found in Supplementary Figure S5. We also found that the majority of peaks contains both the motifs ending with A or T (Supplementary Fig. S6).

In total, 146,000 peaks in induced Raji iBZLF1 cells contained 580,000 TGWGYVW motifs of which 344,000 terminated with $A$ and 236,00 with T (Fig. 2C, Supplementary Figs. S3, S4C, S5). On average each peak was found to contain about 2.6 BZLF1 binding motifs (Fig. 2D, Supplementary Fig. S4D). The analysis also revealed a clear hierarchy of the BZLF1 sequence motifs as shown in Figure 3. The highest affinity at low BZLF1 levels appears to correlate with the motif TGWGCGA, whereas the weakest binding is associated with the motif TGWGYVT to which BZLF1 binds also less frequently at high BZLF1 levels compared with the TGWGYVA motif (Fig. 3).

\section{High BZLF1 levels induce open chromatin at cellular BZLF1 binding sites but a genome-wide loss of open chromatin.}

Next, we investigated the chromatin of EBV's host cells and studied the consequences of inducing EBV's lytic cycle and the binding of BZLF1 to cellular DNA. From our work in press (http://biorxiv.org/cgi/content/short/317354v1) (Schaeffner et al., 2019) we knew that BZLF1 is a viral pioneer factor, binds to nucleosomal DNA, recruits chromatin remodelers such as INO80, and induces the local opening of repressed viral chromatin. To extend this insight, we analyzed the chromatin accessibility of non-induced and induced iBZLF1 Raji cells by ATAC-seq. In these experiments, Raji cells engineered to carry a conditionally expressed BZLF1 gene lacking its transactivation-domain (AD-truncated BZLF1) were used as a negative control.

We combined the ATAC-seq data with the BZLF1 peaks identified at high levels (Fig. 2A) to analyze the local chromatin accessibility as a function of BZLF1 binding. Supplementary Figure S7 illustrates the bioinformatic approach. Average chromatin accessibilities along all 
BZLF1 peaks are shown in Figure 4A. Raw signals and input signals in heatmap representation are shown in Supplementary Figures S8 and S9, respectively.

We analyzed the average coverage of ATAC-seq reads at these sites in the two Raji cell lines that express full-length or the AD-truncated BZLF1 protein in their non-induced and induced states. The visualization in Figure 4A documents the opening of silent, compact chromatin at cellular BZLF1 binding sites that occurs at induced high levels of BZLF1, only. An example is shown in Supplementary Figure S10A and heatmaps are provided in Supplementary Figure S11A. The average peak of chromatin opening co-locates exactly with the peak center of the $>10^{5}$ cellular BZLF1 binding sites in induced cells that express full-length BZLF1. A truncated BZLF1 protein without its transcriptional activation domain does not induce chromatin remodeling (Fig. 4A, Supplementary Fig. S11, panel A4), although it binds inactive chromatin as efficiently as full-length BZLF1 (Bergbauer et al., 2010). This finding clearly supports our view that BZLF1's activation domain recruits chromatin remodelers such as INO80 to silent chromatin (http://biorxiv.org/cgi/content/short/317354v1) (Schaeffner et al., 2019). As a consequence, the previously repressed chromatin becomes accessible and is presumably activated (Fig. 4A, Supplementary Fig. S11, panel A2) or is kept open (Supplementary Fig. 10B). Accessibilities at random locations $(n=1,455,440)$ not linked to BZLF1 binding sites were not affected (inset in Fig. 4A, Supplementary Fig. S11B).

Raji cell chromatin in the latent phase demonstrates a high number of accessible, open regions that are clearly identifiable by ATAC-seq (Supplementary Fig, S10C). We found about 81,000 peaks of accessible cellular chromatin in latent Raji iBZLF1 cells using the MACS2 peak caller and calculated the average ATAC-seq coverage of open chromatin prior to and after induction of EBV's lytic cycle. As shown in Figure 4B, in corresponding heatmaps (Supplementary Fig. S11, panel C), and in a representative IGV browser image (Robinson et al., 2011; Thorvaldsdóttir et al., 2013) shown in Supplementary Figure S10C, we found a strong general reduction of open Raji cell chromatin upon induction of EBV's lytic phase. Reduction of chromatin accessibility was evident at the majority of ATAC-seq peaks previously identified to be accessible during latency (Fig, 4B, Supplementary Fig. 10C).

The data indicate that the induced expression of BZLF1 together with the ensuing activation of EBV's lytic phase modulate the accessibility of cellular chromatin globally. On the contrary, the very many open chromatin loci in latently infected Raji cells become mostly non-accessible whereas chromatin loci bound by BZLF1 open up site-specifically in the very early phase of lytic reactivation.

The induction of EBV's lytic cycle drastically reduces cellular transcripts in Raji cells. 
We investigated the consequences of the induction of EBV's lytic phase and BZLF1's binding to cellular chromatin with respect to transcriptional regulation. RNA-seq experiments were performed in three different experimental layouts:

(i) Steady state RNA transcript levels of parental Raji cells were analyzed and compared with the same cells incubated with doxycycline for six hours (Fig. 5A). Doxycycline did not regulate any genes according to our threshold criteria, which are provided in the figure. The violin plot shown in Figure $5 \mathrm{~A}$ indicates that the log2 fold change of $95 \%$ of the expressed genes, subsequently termed 'population spread', was located in a very narrow range in parental Raji cells (Fig. 5A, bottom panel).

(ii) We repeated the experiment with Raji iBZLF1 AD-truncated cells engineered to express a truncated version of BZLF1 without its transcriptional activation domain (Woellmer et al., 2012). Upon adding doxycycline for 6 hours, no gene was identified to be regulated (Fig. 5B). The population spread in Raji iBZLF1 AD-truncated cells slightly exceeded the range found in the parental Raji cells (Fig. 5B).

(iii) Raji iBZLF1 cells engineered to express the full-length BZLF1 protein were induced by adding doxycycline for six hours (Supplementary Fig. 1) and were analyzed by RNA-seq. We used the ERCC RNA spike-in mix to be prepared for global changes in the cellular transcriptomes, to analyze the basic performance metric of the RNA-seq libraries, and to normalize the data during the steps of subsequent bioinformatic analyses according to this standard. The quantitative detection of the external spike-in RNAs demonstrated the linearity, quality, and reproducibility of the experimental approach (Supplementary Fig. S12).

In Raji iBZLF1 cells we found 91 cellular genes with increased transcript levels, while 7,174 showed a decrease (Fig. 5C). The population spread was much higher when compared to the controls and the median of the population was shifted to a strong negative value indicating that the majority of cellular transcripts was substantially reduced on average. Individual triplicates are shown as boxplots in Supplementary Figure S13.

The top 1,000 most strongly downregulated genes in Raji iBZLF1 cells were used in a KEGG pathway analysis, which identified critical metabolic pathways and pathways in immune cells involved in host cell immune responses, antigen and cytokine signaling (Supplementary Fig. S14).

The results indicate that the short-term induced expression of full-length BZLF1 and subsequent induction of EBV's lytic cycle led to a dramatic and global drop of transcript levels in Raji iBZLF1 cells. Fewer than hundred genes were found upregulated upon BZLF1 
expression, an unexpected finding, because BZLF1 is a known transcriptional activator in the viral genome which also binds to the cellular genome frequently (Fig. 2, Supplementary Fig. S4).

\section{BZLF1 binding sites in proximity to TSS do not correlate with the magnitude of gene regulation.}

Since BZLF1 binds more than 145,000 sites in the cellular chromatin of Raji iBZLF1 cells (Fig. 2, Supplementary Fig. S3), it seemed plausible that BZLF1 regulates promoters of cellular genes similar to the many viral promoters of lytic EBV genes (Bergbauer et al., 2010; Kalla et al., 2010; Woellmer et al., 2012). To address this question, we looked for peaks identified by ChIP-seq within promoter regions of genes found to be regulated in our RNAseq experiments (Fig. 5C). We limited our search to a region $5 \mathrm{~kb}$ upstream to $1 \mathrm{~kb}$ downstream of the TSSs (Fig. 6A). About half of the upregulated genes comprised one or more peaks within the defined limits of their TTSs (Fig. 6A). In Raji iBZLF1 cells, the promoter regions of $63 \%$ downregulated genes did not contain recognizable peaks attributed to BZLF1 binding (Fig. 6A).

We also searched for a possible correlation between the absolute numbers of BZLF1 motifs within the promoter regions and the magnitude of gene regulation. Similar to the results shown in Figure 6A, we did not find an obvious correlation. Certain promoters with few BZLF1 binding motifs were more profoundly regulated than promoters with multiple binding motifs (Fig. 6B). Few cellular genes seemed to be exceptions to this rule in Figure 6B. A very small number of genes contained more than 50 and up to 142 BZLF1 binding motifs within their promoter regions but they were barely regulated upon BZLF1 expression.

Together, the many identified BZLF1 binding motifs in promoter regions of cellular genes did not provide a clear function that could be ascribed to BZLF1. BZLF1 was characterized as a transcription factor of viral promoters, initially, but BZLF1 has also been proposed to act as an enhancer factor (Ramasubramanyan et al., 2015) similar to its cellular homolog AP-1 (Lee et al., 1987; Chavanas et al., 2008). The cellular genome is about eighteen thousand times larger than the EBV genome, contains up to 26,000 genes and an estimated number of up to 9,000,000 regulatory regions (International, 2004; Nguyen et al., 2018). We asked if, upon induction of the lytic phase, EBV governs these regulatory regions at the level of chromatin interactions. We also asked if the frequent binding of BZLF1 to cellular DNA together with the remodeling of silent chromatin may have a discernable effect. Towards this end we selected several up-, down-, and non-regulated cellular genes to look at their interacting chromatin regions, which BZLF1 might regulate to control the expression of cellular genes. 


\section{Induction of EBV's lytic cycle reduces cellular chromatin interactions.}

The regulation of cellular transcription results from an interplay between transcription factors, histone and DNA marks, and chromatin interactions. The latter govern the spatial proximity between enhancers (or repressors) and promoter regions and regulate the activity of genes. The likelihood of functional interactions increases when distant regions are organized into loops by chromatin organizing proteins such as CTCF and cohesin.

We applied the Capture-C technique (Hughes et al., 2014) to study physical chromatin interactions of selected promoters as a function of BZLF1 levels. From our RNA-seq experiment with Raji iBZLF1 cells (Fig. 5C) we chose promoters of genes that were up- or down-regulated but we also included genes that were not affected when BZLF1 was induced. With synthetic single-stranded RNA probes that hybridize to regions of approximately $5 \mathrm{~kb}$ up- and downstream of the transcriptional start sites (TSS) we focused on 53 selected genes and pulled-down their promoter regions.

After data normalization we identified about 1.3 million interactions between the pulled regions and proximal or distal flanking DNA fragments that had been generated by Dpnll cleavage following the Capture-C protocol. For about 170,000 Dpnll fragments a fold change could be calculated in a pair-wise comparison of non-induced Raji iBZLF1 cells with cells induced for 6 or 15 hours ( 0 versus 6 h; 0 versus 15 h). Figure 7A shows a slight increase of total interactions $6 \mathrm{~h}$ after induction of EBV's lytic cycle. About 1,000 Dpnll fragments showed a 2-fold increase of the number of interactions, whereas about 300 Dpnll fragments lost more than half of their interactions. After $15 \mathrm{~h}$ the total number of interactions clearly decreased (Fig. 7B). About 4,000 Dpnll fragments pairs had lost more than half of their interactions while only 74 Dpnll fragment pairs showed a more than 2-fold gain of interactions.

After bioinformatic analysis and data normalization we visualized the close, medium and distant physical chromatin interactions of these promoter regions in a range of 400,000 nucleotides each on both flanks of the TSS (Fig. 8, Supplementary Figs. S15-S22). The yaxes of the graphs indicate the number of chromatin interactions prior to the induction of BZLF1 ( $0 \mathrm{~h}$, grey bars) or six hours (orange bars) and 15 hours (blue bars) after the addition of doxycycline. In addition, we plotted BZLF1 binding sites at low and high levels in Raji iBZLF1 cells.

We visualized the actual situation for several genes to inspect the individual gain and loss of chromatin interactions. Supplementary Figure S15 shows the CD68 gene, which is not regulated (0.99-fold) six hours after induction of the lytic cycle. The number of locus 
interactions of the promoter region with flanking chromatin modestly increased by about $7 \%$ six hours after induction of the lytic cycle relative to the interactions identified prior to its induction. 15 hours after induction the interactions are reduced to about $63 \%$ relative to the non-induced state. A very similar pattern of altered chromatin interactions was found in the locus of the strongly downregulated BTG2 gene (regulated by a factor of 0.02 ; Supplementary Fig. S16) and the upregulated COL2A1 gene (19-fold upregulated; Supplementary Fig. S17). The number of interactions at the BTG2 and COL2A1 loci slightly increased by $12 \%$ and $15 \%$, respectively, six hours post induction, but decreased by $30 \%$ 15 hours after induction following the general trend shown in Figure 7.

The altered numbers of interactions were particular impressive when the strong, longrange interactions of the CXCR4 (Supplementary Fig. S18) and MIR155HG (Supplementary Fig. S19) genes were considered, which are both down-regulated by factors of 0.04 and 0.33 , respectively. The interactions of the CXCR4 gene remained unchanged on average (101\%) while they increased by about $12 \%$ for the MIR155HG gene six hours after induction of BZLF1. After 15 hours, the long-range interactions of the CXCR4 and MIR155HG loci were reduced by $39 \%$ and $34 \%$, respectively.

All analyzed genes but one followed the observed kinetics and showed a considerable loss of chromatin interactions over time. The exception is KCNQ5. Here, the interactions of the flanking region upstream but not downstream of the KCNQ5 gene remained stable or even slightly intensified 15 hours after BZLF1's induction (Supplementary Fig. S20).

Additional examples include E2F2 and ID3 as well as TLR6 and TLR10, which constitute two separate gene clusters as shown in Supplementary Figures S21 and S22 panels A and $B$. Again, these genes are in line with the global reduction of chromatin interactions as a late consequence of BZLF1 expression. Interestingly, the two neighboring genes in both examples share interactions but each individual gene is also engaged in gene-specific chromatin-chromatin contacts.

The MYC gene, which showed a reduction of its steady state transcript levels by a factor of 50 is an extreme example that demonstrates the reduction of chromatin interactions. In the Burkitt lymphoma cell line Raji the $M Y C$ gene is not regulated by its genuine cis-acting elements, but the gene is under the control of the heavy-chain immunoglobulin enhancer due to a translocation between the chromosomes 8 and 14. The $x$-axis in Figure 8 is discontinuous and a vertical red dashed line upstream of the MYC promoter indicates the chromosomal breakpoint. The two Dpnll fragments within the heavy chain enhancer, which make the most frequent contacts with the $M Y C$ promoter regions are indicated by $\mathrm{A}$ and $\mathrm{B}$ (Fig. 8). Both interacting sites lose about $20 \%$ of their contacts with the MYC promoter locus 
already six hours after induction of EBV's lytic cycle. After 15 hours, the number of chromatin contacts at the interacting sites $A$ and $B$ are reduced by $60 \%$ and $80 \%$, respectively. The two distinct Dpnll fragments, A and B, include a 323 nt long repeat (Supplementary Fig. S23, panel A) that comprises 18, partially overlapping BZLF1 sequence motifs (Supplementary Fig. S23, panel B). In our ChIP experiments, both $A$ and $B$ fragments were found to be bound by BZLF1 in Raji iBZLF1 cells (Supplementary Fig. S24, panels A and B).

In summary, all analyzed loci show reduced local and distal chromatin interactions 15 hours after induction of EBV's lytic cycle. The binding of BZLF1 to certain distant interacting sites is often apparent and occasionally impressive as in the example of the MYC gene suggesting that BZLF1 binding to these distal regions directly or indirectly reduces the frequency of chromatin interactions, but this apparent linkage is not supported by our further analysis. Dpnll fragments bound by BZLF1 according to our ChIP-seq data and captured in the Capture-C experiment did not differ from captured Dpnll fragments to which BZLF1 does not bind (Supplementary Fig. S25 panels A and B). It thus appears as if EBV uses so far unknown mechanisms to reduce cellular chromatin interactions and alter the 3D structure of its host cell chromatin in the lytic phase.

\section{DISCUSSION}

After infection and a short period of pre-latency, EBV establishes its latent phase, which results in a very stable host-virus relationship. In this phase, only very few proteins are expressed in vivo probably to avoid the recognition and elimination of virally infected cells by cellular immunity. Upon escape from latency the immediate early viral protein BZLF1 is the first protein of the lytic phase that is expressed. It induces the synthesis of additional viral proteins important for the complete transcriptional activation of the lytic phase, viral factors for the autonomous viral DNA replication and viral genes that fend off the antiviral immunity of the host organism. Therefore, the host cell has to be manipulated and reorganized to free macromolecules, energy, cellular machines, and transport capacity to support directly viral transcription, DNA replication, and viral morphogenesis, processes that also require space and occupy nuclear compartments to allow EBV's reproduction. Since BZLF1 shows a strong structural homology with members of the cellular AP-1 protein family (Petosa et al., 2006) and binds their sequence motifs (Urier et al., 1989) genome wide, we not only examined global changes in the cellular genome and transcriptome, but also asked if BZLF1 is directly involved in these changes.

\section{BZLF1 reaches a high protein level in the lytic phase of B95-8 cells.}


In a first step we investigated the BZFL1 protein levels in the fraction of B95-8 cells that are in the lytic phase of infection. We found very high molecule numbers per cell (Supplementary Fig. S1B) that are also achieved upon doxycycline-mediated induction in our Raji cell model. In this model, the conditional BZLF1 allele has a basal leaky expression, but at this level BZLF1 was incapable of inducing EBV's lytic cycle in Raji iBZLF1 cells (Woellmer et al., 2012) and in HEK 2932089 iBZLF1 cells (Fig. 1, Supplementary Fig. S1C). With this knowledge we assumed that our model truly reflects the functions of BZLF1 in latently infected and lytically induced B cells.

\section{BZLF1 binds two major motifs in the cellular genome with high frequency and specificity.}

At high level BZLF1 binds to several hundred thousand sites in the Raji cell genome, which is in agreement with the diffuse nuclear distribution of BZLF1 (Park et al., 2008). We identified two major sequence motifs, one of which is found in $96 \%$ of all called BZLF1 peaks. The high number of differently composed DNA sequence motifs led us to rank them according to their presumed relative affinities of BZLF1 binding (Fig. 3). Their composition partially confirms previous findings of Ramasubramanyan et. al. (Ramasubramanyan et al., 2015), who, very much in contrast to our study, identified 5,000 BZLF1 binding sites in cellular genomic DNA, only. Our study now extends this set of BZLF1 binding motifs and reveals that BZLF1 also binds closely related motifs that terminate with a thymidine residue (Fig. 3).

The many cellular BZLF1 binding motifs might have an obvious function supporting EBV's life style. A cell that incompletely activates EBV's lytic phase is likely prone to be eliminated by immediate antiviral $T$ cell responses, because the many lytic immunoevasive viral genes are not timely and properly expressed to fend off cytotoxic $\mathrm{CD} 4^{+}$and $\mathrm{CD} 8^{+}$effector $\mathrm{T}$ cells (Ressing et al., 2015). It is therefore plausible that the transition from the latent to the lytic phase operates as a dichotomous switch and not as a rheostat. During a perhaps erratic expression of low BZLF1 levels the cellular genome with its abundant number of high-affinity CpG-ZRE binding motifs might act as a sink abrogating the activation of a subset of viral lytic promoters by chance. Only a strong inducing signal leads to BZLF1 levels sufficient to bind both cellular and viral CpG containing high-affinity motifs (TGWGCGA, Fig. 2C and TGWGCGT, Supplementary Fig. S4C) and, subsequently, the two canonical non-CpG motifs (TGWGYVA, Fig. 2C and TGWGYVT, Supplementary Fig. S4C). We know that BZLF1 must bind certain low affinity binding sites in the viral lytic origin of DNA replication to support efficient viral DNA amplification (Bergbauer et al., 2010; Schepers et al., 1996). Thus, the diverse and abundant BZLF1 binding motifs in cellular DNA $\left(>5 \times 10^{5}\right)$ together with the 85 
identified viral binding motifs likely cooperate to implement a molar switch that only flips when a certain threshold concentration of BZLF1 protein is reached.

\section{The presumed functions of cellular BZLF1 binding sites.}

BZLF1's role in cellular chromatin is not obvious, but it might act at different levels. (i) BZLF1 could induce the expression of a few cellular factors that serve important functions in EBV's lytic phase similar to its role on viral genomic DNA. For example, BZFL1 has to induce the BMLF1-BSLF2 gene (Kenney et al., 1989) such that they together can activate certain early EBV promoters (Chevallier-Greco et al., 1986). BZLF1 acts as a replication factor together with the viral factors BALF2, BALF5, BBLF2/3, BBLF4, BMRF1, and BSLF1 to initiate lytic viral DNA replication (Hammerschmidt and Sugden, 2013), but BZLF1 also induces the expression of these genes mainly via meZRE motifs (Fig. 2C) with methylated CpG dinucleotides (Bergbauer et al., 2010) and probably together with BRLF1. Similarly, BZLF1 has been reported to induce (or repress) numerous cellular genes (Flemington and Speck, 1990; Cayrol and Flemington, 1995; Lu et al., 2000; Morrison et al., 2001; Morrison et al., 2004; Chang et al., 2006; Jones et al., 2007; Hsu et al., 2008; Tsai et al., 2009; Heather et al., 2009; Bristol et al., 2010; Zuo et al., 2011), but a clear picture depicting how BZLF1 regulates cellular targets is lacking. (ii) BZLF1 is known to induce a DNA damage response (DDR), which seems to be needed for the full expression of BZLF1 and other downstream viral factors such as BMRF1. The induction of a DDR requires that BZLF1 binds DNA (Wang'ondu et al., 2015). Thus, cellular BZLF1 binding sites might contribute to DDR induction, but how a DDR could functionally support EBV's lytic phase is uncertain. Lastly, (iii) the many cellular BZLF1 binding sites might be non-functional similar to $46-99 \%$ of all binding sites of 59 different cellular transcription factors (Cusanovich et al., 2014). The binding of transcription factors to these sites did not lead to a measurable change in transcription levels of putative target genes (Cusanovich et al., 2014), but in the case of BZLF1 the many binding sites in cellular chromatin might act as a sink to prevent the erratic induction of EBV's lytic.

\section{BZLF1 induces open chromatin at its cellular binding sites but global chromatin accessibility is reduced in EBV's pre-replicative, lytic phase.}

Regions of open chromatin allow the binding of cellular factors, protein complexes and large nuclear machines. Open chromatin is a prerequisite for chromatin-chromatin interactions that contribute to the formation of topologically associating domains (TADs), chromosome territories and, ultimately, the nuclear architecture. Our genome-wide ATACseq results indicate that the global accessibility of cellular chromatin is considerably reduced upon induction of EBV's lytic cycle (Fig. 4B). Loss of open chromatin is generally linked with 
transcriptional repression, which is in line with our transcriptomic data (Fig. 5). To our knowledge, only during embryonic development the loss of chromatin-chromatin interactions is a noted feature, which is seen in conjunction with the formation of new TADs (Kaaij et al., 2018). Alternatively, an early and general loss or even collapse of discrete chromatinchromatin interactions might prepare for a subsequent spatial regulation of cellular chromatin including the increase in volume of the nucleus of herpesvirus infected cells, when replication compartments or amplification factories form (Monier et al., 2000; Chiu et al., 2013).

Very much in contrast to the global loss of open cellular chromatin, the binding of BZLF1 to silent chromatin increases its local accessibility. BZLF1 is a pioneer factor (Schaeffner et al., 2019) and shares this function with other pioneer factors that bind to repressed and generally inaccessible sequence motifs and recruit chromatin remodelers to mobilize or even evict nucleosomes at and in close proximity of their cognate binding sites. Why BZLF1 opens chromatin at its many cellular binding sites is currently unclear.

\section{EBV's lytic cycle induces a massive reduction of cellular transcripts}

Upon induction of BZLF1 in Raji cells, only few cellular genes are upregulated, while the majority of transcripts $(>7,000)$ are strongly reduced (Fig. 5C). Conversely, viral transcripts are massively upregulated to accumulate to $>140,000$ reads per viral gene (Fig. 1).

The reduction of global transcripts depends on BZLF1's transactivation domain. It could cause a restructuring of the cellular chromatin architecture as seen in Figures 4B, 7, and 8 with a concomitant decrease of cellular transcription or it might induce additional viral genes that indirectly contribute to this reduction. A likely viral candidate is the BGLF5 gene that is highly expressed (87,000 reads, 170-fold induced) already 6 hours after the activation of EBV's lytic phase. BGLF5 is an RNA exonuclease (Buisson et al., 2009) that destroys viral as well as cellular mRNAs nonspecifically (Horst et al., 2012) causing the so-called hostshutoff. Additionally, BGLF5 was described to potentially contribute to immune evasion (Rowe et al., 2007; Zuo et al., 2008) and to support the nuclear translocation of the PABPC protein together with BZLF1. A nuclear accumulation of PABPC leads to hyperadenylated transcripts blocking their nuclear export and translation (Kumar and Glaunsinger, 2010; Park et al., 2014).

Ramasubramanyan et al. also analyzed the transcriptome of Akata cells, an EBV-positive Burkitt lymphoma cell line (Ramasubramanyan et al., 2015), but did not see a global reduction of cellular transcripts in the lytic phase. The authors identified 2,300 genes of which $3 / 4$ were up- and $1 / 4$ down-regulated 24 hours after lytic induction of Akata cells. In 
contrast, we found $99 \%$ of cellular genes down- and $1 \%$ up-regulated in Raji iBZLF1 cells 6 hours post induction (Fig. 5C). The discrepancy between both studies can be explained by the chosen threshold levels of bioinformatic analysis and mainly by the method of normalization. Based on the published literature (Buisson et al., 2009; Horst et al., 2012; Kumar and Glaunsinger, 2010; Park et al., 2014) we expected the mRNA content between non-induced and induced cells to differ substantially. Therefore, we added known molar amounts of polyadenylated ERCC spike-in RNAs to total RNA samples from identical numbers of viable cells. Conventional data processing and normalization approaches mostly rely on average principles and center the mean of the fold change around zero independently of the RNA amount. We know from a conventional analysis of our data that we would have missed the profound global transcriptomic modifications in this model of viral activation had we chosen this bioinformatic approach.

\section{Cellular gene regulation and promoter-binding of BZLF1 are not necessarily linked}

BZLF1 is known to be a promoter factor in the viral genome and was also described to up- or downregulate cellular genes in different cells. (Flemington and Speck, 1990; Cayrol and Flemington, 1995; Lu et al., 2000; Morrison et al., 2001; Morrison et al., 2004; Chang et al., 2006; Jones et al., 2007; Hsu et al., 2008; Tsai et al., 2009; Heather et al., 2009; Bristol et al., 2010; Zuo et al., 2011). A recent report even suggested that BZLF1 might directly or indirectly regulate about $10 \%$ of all protein-encoding genes in B cells (Ramasubramanyan et al., 2015). When we correlated cellular gene regulation and the occurrence of BZLF1 sites in promoter regions, many genes with BZLF1 binding sites were not regulated. This finding is in accordance with previous reports in which transcription factors were found to regulate only a subset of genes with which they are spatially associated (Cusanovich et al., 2014; Gao et al., 2004; Hu et al., 2007). In Raji cells, BZLF1 binding sites could be found in 37-55 \% of apparently regulated genes, only (Fig. 6). This correlative finding contradicts the idea that BZLF1 binds to cellular promoters and induces cellular gene expression. No BZLF1 binding sites were identified in promoters of $45-63 \%$ of genes that are regulated after induced expression of BZLF1. Clearly, at the level of the lytically induced cells, BZLF1 does not follow the rules found in the viral genome, where BZLF1 binds in close proximity to the transcriptional start sites of its regulated genes (Bergbauer et al., 2010).

\section{Upon induction of EBV's lytic cycle, cellular chromatin connections detach.}

Using the Capture-C technique we studied the chromatin structure of 53 selected cellular genes and asked if BZLF1's local binding contributed to their regulation. In latently infected cells we identified many distal regions that contact the promoters' captured regions $5 \mathrm{~kb} /+5 \mathrm{~kb}$ of the transcriptional start sites. Uniformly, the number of chromatin interactions 
rises slightly 6 hours post induction but is substantially reduced at 15 hours irrespective of whether the analyzed genes were up-, down-, or non-regulated.

It is very unlikely that BZLF1 is directly involved in the wide-spread loss of chromatin interactions, because BZLF1 binding and the loss of chromatin interactions do not seem to correlate (Supplementary Fig. S25). The regulation of the MYC locus could be an exception, because BZLF1 might be directly involved in the reduction of chromatin-chromatin contacts between the heavy chain enhancer HCE and the MYC locus (Fig. 8). No BZLF1 binding sites are located in the promoter region of the MYC gene, but it forms strong contacts with $H C E$, which is rich in BZLF1 binding sites. Already six hours after induction, HCE-MYC chromatin interactions decrease considerably and the MYC mRNA level is reduced to two percent, only (Fig. 8).

A BZLF1 regulated lytic viral gene such as BGLF5 is a possible candidate for this task, since it is not only an RNAse but also a DNAse that might affect genomic stability (Baylis et al., 1989). BGLF5 acts as an endonuclease (Zhang et al., 1987; Stolzenberg and Ooka, 1990; Lin et al., 1995) and exonuclease (Lin et al., 1995) and was found to induce DNA damage in the cellular genome and instability of microsatellites in epithelial cells (Wu et al., 2010). A second viral candidate that might contribute to the loss of chromatin interactions is BALF3, which induces DNA strand breaks, meditates genome instability (Chiu et al., 2014a), and supports efficient virion synthesis (Chiu et al., 2014b).

In conclusion, upon induction of EBV's lytic phase we found that cellular chromatinchromatin interactions are lost and the transcriptome of the cell is profoundly reduced. Regions of accessible, hence open chromatin lose their accessibility, but, conversely, BZLF1 binding sites in repressed cellular chromatin gain accessibility. These alterations in cellular chromatin are massive and global suggesting that they contribute to the success of lytic induction and viral de novo synthesis. We speculate that these alterations help to provide space for lytic viral DNA replication (Monier et al., 2000; Chiu et al., 2013) and/or for capsid morphogenesis and mobility (Bosse et al., 2015) and redirect basic cellular functions including transcription, mRNA transport and export such that these resources and functions become available for the synthesis of viral transcripts and viral DNA and additional virusrelated downstream processes.

\section{ACCESSION NUMBERS AND DATA AVAILABILITY}


NGS files have been deposited on ArrayExpress (Kolesnikov et al., 2015) using the webbased submission tool Annotare 2.0 (https://github.com/arrayexpress/annotare2). The data files of interest can be downloaded via https://www.ebi.ac.uk/arrayexpress/ using the following accession numbers:

anti-BZLF1ChIP-seq Raji iBZLF1: http://www.ebi.ac.uk/arrayexpress/experiments/E-MTAB-7788 anti-BZLF1 ChIP-seq parental DG75: to be added.

ATAC-seq: http://www.ebi.ac.uk/arrayexpress/experiments/E-MTAB-7789

RNA-seq: to be added.

Capture-C: to be added.

\section{SUPPLEMENTARY DATA}

Supplementary Data are available in separate files and include 25 Supplementary Figures, their figure legends, and three Supplementary Tables.

\section{ACKNOWLEDGEMENT}

We thank Alexander Graf (Laboratory for Functional Genome Analysis, Gene Center, Ludwig Maximilians University Munich, Munich, Germany) for the introduction to the Galaxy suit and the initial analysis of RNA-seq data, Sylvia Mallok (Laboratory for Functional Genome Analysis, Gene Center, Ludwig Maximilians University Munich, Munich, Germany) for the help with the preparation of the RNA-seq and Capture-C libraries, Tamas Schauer (Molecular Biology Division, Biomedical Center, Faculty of Medicine, Ludwig-Maximilians University Munich, Planegg-Martinsried, Germany) for the code for ERCC spike-in normalization, Thomas Schwarzmayr (Institute of Human Genetics, Helmholtz Zentrum München, Germany) for the code for the visualization of ERCC spike-in NGS sequencing reads, and James Davies (Trinity College, Bristol, UK) for supporting our understanding of the Capture- $C$ analysis.

\section{FUNDING}

This work was financially supported by grants of the Deutsche Forschungsgemeinschaft [grant numbers SFB1064/TP A13, SFB-TR36/TP A04], Deutsche Krebshilfe [grant number 70112875], and National Cancer Institute [grant number CA70723] to W.H.. 


\title{
AUTHORS CONTRIBUTIONS
}

\author{
A.B., P.M.-G., S.K., H.B., F.M.C., D.P., T.S., and W.H. designed and performed experiments \\ and analyzed data. A.B., G.S., T.S., and W.H. designed and conceived the project. A.B. and \\ W.H. wrote the manuscript.
}

\section{CONFLICT OF INTEREST}

The authors declare no competing interests. 


\section{REFERENCES}

Afgan E, Baker D, van den Beek M, Blankenberg D, Bouvier D, Čech M, Chilton J, Clements D, Coraor N, Eberhard C, Grüning B, Guerler A, Hillman-Jackson J, Von Kuster G, Rasche E, Soranzo N, Turaga N, Taylor J, Nekrutenko A, Goecks J (2016) The Galaxy platform for accessible, reproducible and collaborative biomedical analyses: 2016 update. Nucleic Acids Res 44:W3-W10. doi: 10.1093/nar/gkw343

Albanese M, Tagawa T, Buschle A, Hammerschmidt W (2017) microRNAs of Epstein-Barr virus control innate and adaptive anti-viral immunity. J Virol 91:e01667-16. doi: 10.1128/JVI.01667-16

Ameyar M, Wisniewska M, Weitzman JB (2003) A role for AP-1 in apoptosis: the case for and against. Biochimie 85:747-752

Anders S, Pyl PT, Huber W (2015) HTSeq--a Python framework to work with highthroughput sequencing data. Bioinformatics 31:166-169. doi: 10.1093/bioinformatics/btu638

Bailey TL (2011) DREME: motif discovery in transcription factor ChIP-seq data. Bioinformatics 27:1653-1659. doi: 10.1093/bioinformatics/btr261

Bailey TL, Johnson J, Grant CE, Noble WS (2015) The MEME Suite. Nucleic Acids Res 43:W39-49. doi: 10.1093/nar/gkv416

Barter RL, Yu B (2017) Superheat: An R package for creating beautiful and extendable heatmaps for visualizing complex data. 1-26

Baylis SA, Purifoy DJ, Littler E (1989) The characterization of the EBV alkaline deoxyribonuclease cloned and expressed in E. coli. Nucleic Acids Res 17:7609-7622

Ben-Bassat H, Goldblum N, Mitrani S, Goldblum T, Yoffey JM, Cohen MM, Bentwich Z, Ramot B, Klein E, Klein G (1977) Establishment in continuous culture of a new type of lymphocyte from a "Burkitt like" malignant lymphoma (line D.G.-75). Int J Cancer 19:27-33

Bergbauer M, Kalla M, Schmeinck A, Gobel C, Rothbauer U, Eck S, Benet-Pages A, Strom TM, Hammerschmidt W (2010) CpG-methylation regulates a class of Epstein-Barr virus promoters. PLoS Pathog 6:e1001114. doi: 10.1371/journal.ppat.1001114

Bhende PM, Seaman WT, Delecluse HJ, Kenney SC (2004) The EBV lytic switch protein, Z, preferentially binds to and activates the methylated viral genome. Nat Genet 36:10991104. doi: $10.1038 / \mathrm{ng} 1424$

Bornkamm GW, Berens C, Kuklik-Roos C, Bechet JM, Laux G, Bachl J, Korndoerfer M, Schlee M, Holzel M, Malamoussi A, Chapman RD, Nimmerjahn F, Mautner J, Hillen W, Bujard H, Feuillard J (2005) Stringent doxycycline-dependent control of gene activities using an episomal one-vector system. Nucleic Acids Res 33:e137 
Bosse JB, Hogue IB, Feric M, Thiberge SY, Sodeik B, Brangwynne CP, Enquist LW (2015) Remodeling nuclear architecture allows efficient transport of herpesvirus capsids by diffusion. Proc Natl Acad Sci U S A 112:E5725-33. doi: 10.1073/pnas.1513876112

Bristol JA, Robinson AR, Barlow EA, Kenney SC (2010) The Epstein-Barr virus BZLF1 protein inhibits tumor necrosis factor receptor 1 expression through effects on cellular C/EBP proteins. J Virol 84:12362-12374. doi: 10.1128/JVI.00712-10

Buenrostro JD, Giresi PG, Zaba LC, Chang HY, Greenleaf WJ (2013) Transposition of native chromatin for fast and sensitive epigenomic profiling of open chromatin, DNA-binding proteins and nucleosome position. Nat Methods 10:1213-1218. doi: 10.1038/nmeth.2688

Buisson M, Géoui T, Flot D, Tarbouriech N, Ressing ME, Wiertz EJ, Burmeister WP (2009) A bridge crosses the active-site canyon of the Epstein-Barr virus nuclease with DNase and RNase activities. J Mol Biol 391:717-728. doi: 10.1016/j.jmb.2009.06.034

Cayrol C, Flemington EK (1995) Identification of cellular target genes of the Epstein-Barr virus transactivator Zta: activation of transforming growth factor beta igh3 (TGF-beta igh3) and TGF-beta 1. J Virol 69:4206-4212

Chang W (2014) Extrafont: Tools for using fonts.

Chang Y, Lee HH, Chen YT, Lu J, Wu SY, Chen CW, Takada K, Tsai CH (2006) Induction of the early growth response 1 gene by Epstein-Barr virus lytic transactivator Zta. J Virol 80:7748-7755. doi: 10.1128/JVI.02608-05

Chang YN, Dong DL, Hayward GS, Hayward SD (1990) The Epstein-Barr virus Zta transactivator: a member of the bZIP family with unique DNA-binding specificity and a dimerization domain that lacks the characteristic heptad leucine zipper motif. $\mathrm{J}$ Virol 64:3358-3369

Chavanas S, Adoue V, Méchin MC, Ying S, Dong S, Duplan H, Charveron M, Takahara H, Serre G, Simon M (2008) Long-range enhancer associated with chromatin looping allows AP-1 regulation of the peptidylarginine deiminase 3 gene in differentiated keratinocyte. PLoS One 3:e3408. doi: 10.1371/journal.pone.0003408

Chevallier-Greco A, Manet E, Chavrier P, Mosnier C, Daillie J, Sergeant A (1986) Both Epstein-Barr virus (EBV)-encoded trans-acting factors, EB1 and EB2, are required to activate transcription from an EBV early promoter. Embo J 5:3243-3249

Chiu SH, Wu CC, Fang CY, Yu SL, Hsu HY, Chow YH, Chen JY (2014a) Epstein-Barr virus BALF3 mediates genomic instability and progressive malignancy in nasopharyngeal carcinoma. Oncotarget 5:8583-8601. doi: 10.18632/oncotarget.2323

Chiu SH, Wu MC, Wu CC, Chen YC, Lin SF, Hsu JT, Yang CS, Tsai CH, Takada K, Chen MR, Chen JY (2014b) Epstein-Barr virus BALF3 has nuclease activity and mediates mature virion production during the lytic cycle. J Virol 88:4962-4975. doi: 10.1128/JVI.00063-14

Chiu YF, Sugden AU, Sugden B (2013) Epstein-Barr viral productive amplification reprograms nuclear architecture, DNA replication, and histone deposition. Cell Host Microbe 14:607-618. doi: 10.1016/j.chom.2013.11.009 
Corces MR, Trevino AE, Hamilton EG, Greenside PG, Sinnott-Armstrong NA, Vesuna S, Satpathy AT, Rubin AJ, Montine KS, Wu B, Kathiria A, Cho SW, Mumbach MR, Carter AC, Kasowski M, Orloff LA, Risca VI, Kundaje A, Khavari PA, Montine TJ, Greenleaf WJ, Chang HY (2017) An improved ATAC-seq protocol reduces background and enables interrogation of frozen tissues. Nat Methods 14:959-962. doi: $10.1038 /$ nmeth.4396

Countryman J, Miller G (1985) Activation of expression of latent Epstein-Barr herpesvirus after gene transfer with a small cloned subfragment of heterogeneous viral DNA. Proc Natl Acad Sci U S A 82:4085-4089. doi: 10.1073/pnas.82.12.4085

Cusanovich DA, Pavlovic B, Pritchard JK, Gilad Y (2014) The functional consequences of variation in transcription factor binding. PLoS Genet 10:e1004226. doi: 10.1371/journal.pgen.1004226

Decaussin G, Leclerc V, Ooka T (1995) The lytic cycle of Epstein-Barr virus in the nonproducer Raji line can be rescued by the expression of a 135-kilodalton protein encoded by the BALF2 open reading frame. J Virol 69:7309-7314

Delecluse HJ, Hilsendegen T, Pich D, Zeidler R, Hammerschmidt W (1998) Propagation and recovery of intact, infectious Epstein-Barr virus from prokaryotic to human cells. Proc Natl Acad Sci U S A 95:8245-8250. doi: 10.1073/pnas.95.14.8245

Dickerson SJ, Xing Y, Robinson AR, Seaman WT, Gruffat H, Kenney SC (2009) Methylation-dependent binding of the Epstein-Barr virus BZLF1 protein to viral promoters. PLoS Pathog 5:e1000356. doi: 10.1371/journal.ppat.1000356

Eferl R, Wagner EF (2003) AP-1: a double-edged sword in tumorigenesis. Nat Rev Cancer 3:859-868. doi: 10.1038/nrc1209

Farrell PJ, Rowe DT, Rooney CM, Kouzarides T (1989) Epstein-Barr virus BZLF1 transactivator specifically binds to a consensus AP-1 site and is related to c-fos. EMBO $\mathrm{J}$ 8:127-132

Feng J, Liu T, Qin B, Zhang Y, Liu XS (2012) Identifying ChIP-seq enrichment using MACS. Nat Protoc 7:1728-1740. doi: 10.1038/nprot.2012.101

Fixman ED, Hayward GS, Hayward SD (1992) trans-acting requirements for replication of Epstein-Barr virus ori-Lyt. J Virol 66:5030-5039

Fixman ED, Hayward GS, Hayward SD (1995) Replication of Epstein-Barr virus oriLyt: lack of a dedicated virally encoded origin-binding protein and dependence on Zta in cotransfection assays. J Virol 69:2998-3006

Flemington E, Speck SH (1990) Epstein-Barr virus BZLF1 trans activator induces the promoter of a cellular cognate gene, c-fos. J Virol 64:4549-4552

Flower K, Thomas D, Heather J, Ramasubramanyan S, Jones S, Sinclair AJ (2011) Epigenetic control of viral life-cycle by a DNA-methylation dependent transcription factor. PLoS One 6:e25922. doi: 10.1371/journal.pone.0025922 
Gao X, Wang H, Sairenji T (2004) Inhibition of Epstein-Barr virus (EBV) reactivation by short interfering RNAs targeting p38 mitogen-activated protein kinase or c-myc in EBVpositive epithelial cells. J Virol 78:11798-11806

Graham FL, Smiley J, Russell WC, Nairn R (1977) Characteristics of a human cell line transformed by DNA from human adenovirus type 5. J Gen Virol 36:59-74. doi: 10.1099/0022-1317-36-1-59

Gustems M, Woellmer A, Rothbauer U, Eck SH, Wieland T, Lutter D, Hammerschmidt W (2014) c-Jun/c-Fos heterodimers regulate cellular genes via a newly identified class of methylated DNA sequence motifs. Nucleic Acids Res 42:3059-3072. doi: 10.1093/nar/gkt1323

Hammerschmidt W, Sugden B (2013) Replication of Epstein-Barr viral DNA. Cold Spring Harb Perspect Biol 5:513-525. doi: 10.1101/cshperspect.a013029

Hatfull G, Bankier AT, Barrell BG, Farrell PJ (1988) Sequence analysis of Raji Epstein-Barr virus DNA. Virology 164:334-340

Heather J, Flower K, Isaac S, Sinclair AJ (2009) The Epstein-Barr virus Iytic cycle activator Zta interacts with methylated ZRE in the promoter of host target gene egr1. J Gen Virol 90:1450-1454. doi: 10.1099/vir.0.007922-0

Horst D, Burmeister WP, Boer IG, van Leeuwen D, Buisson M, Gorbalenya AE, Wiertz EJ, Ressing ME (2012) The "Bridge" in the Epstein-Barr virus alkaline exonuclease protein BGLF5 contributes to shutoff activity during productive infection. J Virol 86:9175-9187. doi: $10.1128 / J V I .00309-12$

Hsu M, Wu SY, Chang SS, Su IJ, Tsai CH, Lai SJ, Shiau AL, Takada K, Chang Y (2008) Epstein-Barr virus lytic transactivator Zta enhances chemotactic activity through induction of interleukin-8 in nasopharyngeal carcinoma cells. J Virol 82:3679-3688. doi: 10.1128/JVI.02301-07

Hu Z, Killion PJ, lyer VR (2007) Genetic reconstruction of a functional transcriptional regulatory network. Nat Genet 39:683-687. doi: 10.1038/ng2012

Hughes JR, Roberts N, McGowan S, Hay D, Giannoulatou E, Lynch M, De Gobbi M, Taylor S, Gibbons R, Higgs DR (2014) Analysis of hundreds of cis-regulatory landscapes at high resolution in a single, high-throughput experiment. Nat Genet 46:205-212. doi: $10.1038 / \mathrm{ng} .2871$

International HGSC (2004) Finishing the euchromatic sequence of the human genome. Nature 431:931-945. doi: 10.1038/nature03001

Jochum S, Ruiss R, Moosmann A, Hammerschmidt W, Zeidler R (2012) RNAs in EpsteinBarr virions control early steps of infection. Proc Natl Acad Sci U S A 109:E1396-404. doi: 10.1073/pnas.1115906109

Jones RJ, Seaman WT, Feng WH, Barlow E, Dickerson S, Delecluse HJ, Kenney SC (2007) Roles of lytic viral infection and IL- 6 in early versus late passage lymphoblastoid cell lines and EBV-associated lymphoproliferative disease. Int J Cancer 121:1274-1281. doi: $10.1002 / \mathrm{jjc} .22839$ 
Kaaij LJT, van der Weide RH, Ketting RF, de Wit E (2018) Systemic Loss and Gain of Chromatin Architecture throughout Zebrafish Development. Cell Rep 24:1-10.e4. doi: 10.1016/j.celrep.2018.06.003

Kalla M, Gobel C, Hammerschmidt W (2012) The lytic phase of Epstein-Barr virus requires a viral genome with 5-methylcytosine residues in CpG sites. J Virol 86:447-458. doi: 10.1128/JVI.06314-11

Kalla M, Hammerschmidt W (2012) Human B cells on their route to latent infection--early but transient expression of lytic genes of Epstein-Barr virus. Eur J Cell Biol 91:65-69. doi: 10.1016/j.ejcb.2011.01.014

Kalla M, Schmeinck A, Bergbauer M, Pich D, Hammerschmidt W (2010) AP-1 homolog BZLF1 of Epstein-Barr virus has two essential functions dependent on the epigenetic state of the viral genome. Proc Natl Acad Sci U S A 107:850-855. doi: 10.1073/pnas.0911948107

Kenney S, Holley-Guthrie E, Mar EC, Smith M (1989) The Epstein-Barr virus BMLF1 promoter contains an enhancer element that is responsive to the BZLF1 and BRLF1 transactivators. J Virol 63:3878-3883

Kenney SC, Mertz JE (2014) Regulation of the latent-lytic switch in Epstein-Barr virus. Semin Cancer Biol 26:60-68. doi: 10.1016/j.semcancer.2014.01.002

Kim D, Pertea G, Trapnell C, Pimentel H, Kelley R, Salzberg SL (2013) TopHat2: accurate alignment of transcriptomes in the presence of insertions, deletions and gene fusions. Genome Biol 14:R36. doi: 10.1186/gb-2013-14-4-r36

Kolesnikov N, Hastings E, Keays M, Melnichuk O, Tang YA, Williams E, Dylag M, Kurbatova N, Brandizi M, Burdett T, Megy K, Pilicheva E, Rustici G, Tikhonov A, Parkinson H, Petryszak R, Sarkans U, Brazma A (2015) ArrayExpress update--simplifying data submissions. Nucleic Acids Res 43:D1113-6. doi: 10.1093/nar/gku1057

Kumar GR, Glaunsinger BA (2010) Nuclear import of cytoplasmic poly(A) binding protein restricts gene expression via hyperadenylation and nuclear retention of mRNA. Mol Cell Biol 30:4996-5008. doi: 10.1128/MCB.00600-10

Laichalk LL, Thorley-Lawson DA (2005) Terminal differentiation into plasma cells initiates the replicative cycle of Epstein-Barr virus in vivo. J Virol 79:1296-1307

Langmead B, Salzberg SL (2012) Fast gapped-read alignment with Bowtie 2. Nat Methods 9:357-359. doi: 10.1038/nmeth.1923

Langmead B, Trapnell C, Pop M, Salzberg SL (2009) Ultrafast and memory-efficient alignment of short DNA sequences to the human genome. Genome Biol 10:R25. doi: 10.1186/gb-2009-10-3-r25

Lee W, Mitchell P, Tjian R (1987) Purified transcription factor AP-1 interacts with TPAinducible enhancer elements. Cell 49:741-752

Li H, Handsaker B, Wysoker A, Fennell T, Ruan J, Homer N, Marth G, Abecasis G, Durbin R, 1000 GPDPS (2009) The Sequence Alignment/Map format and SAMtools. Bioinformatics 25:2078-2079. doi: 10.1093/bioinformatics/btp352 
Lieberman PM, Hardwick JM, Sample J, Hayward GS, Hayward SD (1990) The zta transactivator involved in induction of lytic cycle gene expression in Epstein-Barr virusinfected lymphocytes binds to both AP-1 and ZRE sites in target promoter and enhancer regions. J Virol 64:1143-1155

Lin SF, Hsu TY, Liu MY, Lin LS, Yang HL, Chen JY, Yang CS (1995) Characterization of Epstein-Barr virus DNase and its interaction with the major DNA binding protein. Virology 208:712-722. doi: 10.1006/viro.1995.1203

Love MI, Huber W, Anders S (2014) Moderated estimation of fold change and dispersion for RNA-seq data with DESeq2. Genome Biol 15:550. doi: 10.1186/s13059-014-0550-8

Lu J, Chen SY, Chua HH, Liu YS, Huang YT, Chang Y, Chen JY, Sheen TS, Tsai CH (2000) Upregulation of tyrosine kinase TKT by the Epstein-Barr virus transactivator Zta. J Virol 74:7391-7399

Magoc T, Salzberg SL (2011) FLASH: fast length adjustment of short reads to improve genome assemblies. Bioinformatics 27:2957-2963. doi: 10.1093/bioinformatics/btr507

Marazzi I, Ho JS, Kim J, Manicassamy B, Dewell S, Albrecht RA, Seibert CW, Schaefer U, Jeffrey KL, Prinjha RK, Lee K, García-Sastre A, Roeder RG, Tarakhovsky A (2012) Suppression of the antiviral response by an influenza histone mimic. Nature 483:428433. doi: $10.1038 /$ nature 10892

Miller G, Lipman M (1973) Release of infectious Epstein-Barr virus by transformed marmoset leukocytes. Proc Natl Acad Sci U S A 70:190-194

Monier K, Armas JC, Etteldorf S, Ghazal P, Sullivan KF (2000) Annexation of the interchromosomal space during viral infection. Nat Cell Biol 2:661-665. doi: $10.1038 / 35023615$

Morrison TE, Mauser A, Klingelhutz A, Kenney SC (2004) Epstein-Barr virus immediateearly protein BZLF1 inhibits tumor necrosis factor alpha-induced signaling and apoptosis by downregulating tumor necrosis factor receptor 1 . J Virol 78:544-549

Morrison TE, Mauser A, Wong A, Ting JP, Kenney SC (2001) Inhibition of IFN-gamma signaling by an Epstein-Barr virus immediate-early protein. Immunity 15:787-799

Neuwirth E (2014) RColorBrewer: ColorBrewer palettes.

Nguyen QH, Tellam RL, Naval-Sanchez M, Porto-Neto LR, Barendse W, Reverter A, Hayes B, Kijas J, Dalrymple BP (2018) Mammalian genomic regulatory regions predicted by utilizing human genomics, transcriptomics, and epigenetics data. Gigascience 7:1-17. doi: 10.1093/gigascience/gix136

Park R, El-Guindy A, Heston L, Lin SF, Yu KP, Nagy M, Borah S, Delecluse HJ, Steitz J, Miller G (2014) Nuclear translocation and regulation of intranuclear distribution of cytoplasmic poly(A)-binding protein are distinct processes mediated by two Epstein Barr virus proteins. PLoS One 9:e92593. doi: 10.1371/journal.pone.0092593

Park R, Heston L, Shedd D, Delecluse HJ, Miller G (2008) Mutations of amino acids in the DNA-recognition domain of Epstein-Barr virus ZEBRA protein alter its sub-nuclear 
localization and affect formation of replication compartments. Virology 382:145-162. doi: 10.1016/j.virol.2008.09.009

Petosa C, Morand P, Baudin F, Moulin M, Artero JB, Muller CW (2006) Structural basis of lytic cycle activation by the Epstein-Barr virus ZEBRA protein. Mol Cell 21:565-572. doi: 10.1016/j.molcel.2006.01.006

Phanstiel DH, Van Bortle K, Spacek D, Hess GT, Shamim MS, Machol I, Love MI, Aiden EL, Bassik MC, Snyder MP (2017) Static and Dynamic DNA Loops form AP-1-Bound Activation Hubs during Macrophage Development. Mol Cell 67:1037-1048.e6. doi: 10.1016/j.molcel.2017.08.006

Polack A, Delius H, Zimber U, Bornkamm GW (1984) Two deletions in the Epstein-Barr virus genome of the Burkitt lymphoma nonproducer line Raji. Virology 133:146-157

Pulvertaft JV (1964) Cytology of Burkitt's tumour (African lymphoma). Lancet 1:238-240

Qian S, Fan W, Liu T, Wu M, Zhang H, Cui X, Zhou Y, Hu J, Wei S, Chen H, Li X, Qian P (2017) Seneca Valley Virus Suppresses Host Type I Interferon Production by Targeting Adaptor Proteins MAVS, TRIF, and TANK for Cleavage. J Virol 9110.1128/JVI.0082317

Quinlan AR, Hall IM (2010) BEDTools: a flexible suite of utilities for comparing genomic features. Bioinformatics 26:841-842. doi: 10.1093/bioinformatics/btq033

Quinlan MP, Chen LB, Knipe DM (1984) The intranuclear location of a herpes simplex virus DNA-binding protein is determined by the status of viral DNA replication. Cell 36:857868

Team RC (2018) R: A language and environment for statistical computing.

Ramasubramanyan S, Osborn K, Al-Mohammad R, Naranjo Perez-Fernandez IB, Zuo J, Balan N, Godfrey A, Patel H, Peters G, Rowe M, Jenner RG, Sinclair AJ (2015) Epstein-Barr virus transcription factor Zta acts through distal regulatory elements to directly control cellular gene expression. Nucleic Acids Res 43:3563-3577. doi: $10.1093 /$ nar/gkv212

Ressing ME, van Gent M, Gram AM, Hooykaas MJ, Piersma SJ, Wiertz EJ (2015) Immune Evasion by Epstein-Barr Virus. Curr Top Microbiol Immunol 391:355-381. doi: 10.1007/978-3-319-22834-1_12

Robinson JT, Thorvaldsdóttir H, Winckler W, Guttman M, Lander ES, Getz G, Mesirov JP (2011) Integrative genomics viewer. Nat Biotechnol 29:24-26. doi: 10.1038/nbt.1754

Rowe M, Glaunsinger B, van Leeuwen D, Zuo J, Sweetman D, Ganem D, Middeldorp J, Wiertz EJ, Ressing ME (2007) Host shutoff during productive Epstein-Barr virus infection is mediated by BGLF5 and may contribute to immune evasion. Proc Natl Acad Sci U S A 104:3366-3371. doi: 10.1073/pnas.0611128104

Schaeffner M, Mrozek-Gorska P, Buschle A, Woellmer A, Tagawa T, Cernilogar FM, Schotta G, Krietenstein N, Lieleg C, Korber P, Hammerschmidt W (2019) BZLF1 interacts with chromatin remodelers promoting escape from latent infections with Epstein-Barr virus. Life Science Alliance (in press) 
Schäffner M (2015) Chromatin remodeling in Epstein-Barr virus after induction of the lytic phase: molecular characterization of the role of BZLF1 and its interactions. Dissertation, Ludwig Maximilians-University

Schepers A, Pich D, Hammerschmidt W (1993) A transcription factor with homology to the AP-1 family links RNA transcription and DNA replication in the lytic cycle of EpsteinBarr virus. EMBO J 12:3921-3929

Schepers A, Pich D, Hammerschmidt W (1996) Activation of oriLyt, the lytic origin of DNA replication of Epstein-Barr virus, by BZLF1. Virology 220:367-376. doi: 10.1006/viro.1996.0325

Shaulian E, Karin M (2001) AP-1 in cell proliferation and survival. Oncogene 20:2390-2400. doi: $10.1038 /$ sj.onc.1204383

Shaulian E, Karin M (2002) AP-1 as a regulator of cell life and death. Nat Cell Biol 4:E131-6. doi: 10.1038/ncb0502-e131

Steinbrück L, Gustems M, Medele S, Schulz TF, Lutter D, Hammerschmidt W (2015) K1 and K15 of Kaposi's sarcoma-associated herpesvirus are partial functional homologues of latent membrane protein 2A of Epstein-Barr virus. J Virol 89:7248-7261. doi: 10.1128/JVI.00839-15

Stolzenberg MC, Ooka T (1990) Purification and properties of Epstein-Barr virus DNase expressed in Escherichia coli. J Virol 64:96-104

Takada K, Shimizu N, Sakuma S, Ono Y (1986) Transactivation of the latent Epstein-Barr virus (EBV) genome after transfection of the EBV DNA fragment. J Virol 57:1016-1022

Thorvaldsdóttir H, Robinson JT, Mesirov JP (2013) Integrative Genomics Viewer (IGV): highperformance genomics data visualization and exploration. Brief Bioinform 14:178-192. doi: $10.1093 / \mathrm{bib} / \mathrm{bbs} 017$

Tsai SC, Lin SJ, Chen PW, Luo WY, Yeh TH, Wang HW, Chen CJ, Tsai CH (2009) EBV Zta protein induces the expression of interleukin-13, promoting the proliferation of EBVinfected B cells and lymphoblastoid cell lines. Blood 114:109-118. doi: 10.1182/blood2008-12-193375

Urier G, Buisson M, Chambard P, Sergeant A (1989) The Epstein-Barr virus early protein EB1 activates transcription from different responsive elements including AP-1 binding sites. EMBO J 8:1447-1453

Vierbuchen T, Ling E, Cowley CJ, Couch CH, Wang X, Harmin DA, Roberts CWM, Greenberg ME (2017) AP-1 Transcription Factors and the BAF Complex Mediate Signal-Dependent Enhancer Selection. Mol Cell 68:1067-1082.e12. doi: 10.1016/j.molcel.2017.11.026

Wang'ondu R, Teal S, Park R, Heston L, Delecluse H, Miller G (2015) DNA Damage Signaling Is Induced in the Absence of Epstein-Barr Virus (EBV) Lytic DNA Replication and in Response to Expression of ZEBRA. PLoS One 10:e0126088. doi: 10.1371/journal.pone.0126088 
Wen W, Iwakiri D, Yamamoto K, Maruo S, Kanda T, Takada K (2007) Epstein-Barr virus BZLF1 gene, a switch from latency to lytic infection, is expressed as an immediateearly gene after primary infection of B lymphocytes. J Virol 81:1037-1042. doi: 10.1128/JVI.01416-06

Woellmer A, Arteaga-Salas JM, Hammerschmidt W (2012) BZLF1 governs CpG-methylated chromatin of Epstein-Barr virus reversing epigenetic repression. PLoS Pathog 8:e1002902. doi: 10.1371/journal.ppat.1002902

Wu CC, Liu MT, Chang YT, Fang CY, Chou SP, Liao HW, Kuo KL, Hsu SL, Chen YR, Wang PW, Chen YL, Chuang HY, Lee CH, Chen M, Wayne Chang WS, Chen JY (2010) Epstein-Barr virus DNase (BGLF5) induces genomic instability in human epithelial cells. Nucleic Acids Res 38:1932-1949. doi: 10.1093/nar/gkp1169

Young LS, Lau R, Rowe M, Niedobitek G, Packham G, Shanahan F, Rowe DT, Greenspan D, Greenspan JS, Rickinson AB, et A (1991) Differentiation-associated expression of the Epstein-Barr virus BZLF1 transactivator protein in oral hairy leukoplakia. J Virol 65:2868-2874

Zanconato F, Forcato M, Battilana G, Azzolin L, Quaranta E, Bodega B, Rosato A, Bicciato S, Cordenonsi M, Piccolo S (2015) Genome-wide association between YAP/TAZ/TEAD and AP-1 at enhancers drives oncogenic growth. Nat Cell Biol 17:1218-1227. doi: $10.1038 /$ ncb3216

Zhang CX, Decaussin G, de Turenne Tessier M, Daillie J, Ooka T (1987) Identification of an Epstein-Barr virus-specific desoxyribonuclease gene using complementary DNA. Nucleic Acids Res 15:2707-2717

Zhang Y, Liu T, Meyer CA, Eeckhoute J, Johnson DS, Bernstein BE, Nusbaum C, Myers RM, Brown M, Li W, Liu XS (2008) Model-based analysis of ChIP-Seq (MACS). Genome Biol 9:R137. doi: 10.1186/gb-2008-9-9-r137

Zheng $\mathrm{YH}$, Jeang $\mathrm{KT}$, Tokunaga $\mathrm{K}$ (2012) Host restriction factors in retroviral infection: promises in virus-host interaction. Retrovirology 9:112. doi: 10.1186/1742-4690-9-112

Zhou H, Zarubin T, Ji Z, Min Z, Zhu W, Downey JS, Lin S, Han J (2005) Frequency and distribution of AP-1 sites in the human genome. DNA Res 12:139-150. doi: 10.1093/dnares/12.2.139

Zuo J, Thomas W, van Leeuwen D, Middeldorp JM, Wiertz EJ, Ressing ME, Rowe M (2008) The DNase of gammaherpesviruses impairs recognition by virus-specific CD8+ T cells through an additional host shutoff function. J Virol 82:2385-2393. doi: 10.1128/JVI.01946-07

Zuo J, Thomas WA, Haigh TA, Fitzsimmons L, Long HM, Hislop AD, Taylor GS, Rowe M (2011) Epstein-Barr virus evades CD4+ T cell responses in lytic cycle through BZLF1mediated downregulation of CD74 and the cooperation of $\mathrm{vBcl}-2$. PLoS Pathog 7:e1002455. doi: 10.1371/journal.ppat.1002455 


\section{FIGURE LEGENDS}

Figure 1.

\section{Expression of lytic viral genes in Raji cells upon induced expression of BZLF1.}

The induction of BZLF1 in Raji iBZLF1 cells for 6 hours resulted in the regulation of viral genes in the range of 0.3 fold (EBNA2) to 300 fold (BDLF3.5). The x-axis shows the mean of the sequencing reads after ERCC normalization, the y-axis shows the log2-fold change of gene expression in non-induced cells compared with cells induced with doxycycline for 6 hours. The blue dots indicate the detected 63 ERCC spike-in RNA reads, which were used to normalize the data set. Only genes with more than 20 sequencing reads (indicated by the purple dashed vertical line) that were either up-regulated (61 genes, $>2.5$ fold, green dashed horizontal line) or down-regulated ( 2 genes, $<0.4$ fold, green dashed horizontal line) were taken into consideration. Viral genes outside this range are greyed out, while genes that are essential, important or known to support viral DNA replication are indicated as orange dots and are described in detail in the text. Supplementary Table S1 provides the complete list of BZLF1 regulated viral genes.

\section{Figure 2}

\section{Identification of ChIP-seq peaks and BZLF1 binding motifs in chromatin of Raji iBZLF1 cells.}

(A) Peaks identified with the BZ1 antibody directed against BZLF1 at low and high levels (i.e. non-induced and induced levels, respectively) of BZLF1 in EBV-positive Raji iBZLF1 cells.

(B) The intersections of the 'low' and 'high' peak sets with at least one identified motif indicate that the majority of low-level peaks are maintained when BZLF1 is highly induced. The abundance of peaks increases up to 5-fold at high BZLF1 levels compared with the peak number at low BZLF1 levels.

(C) At low BZLF1 levels the known BZLF1 binding motif TGWGCGA predominates in individual peaks. At high BZLF1 levels the less specific TGWGYVA motif was identified as the major motif, which encompasses the previously identified meZRE motif TGWGCGA (Bergbauer et al., 2010). The Supplementary Figure S3 shows the detailed statistics and the relative abundance of frequent motif compositions.

(D) The average frequencies of the number of BZLF1 motifs per ChIP-seq peak is provided. 


\section{Figure 3}

\section{Motif abundance as a function of BZLF1 levels in Raji iBZLF1 cells.}

The number of the four BZLF1 binding motifs found in ChIP-seq peaks is plotted at low and high expression levels of BZLF1. At both levels the number of motifs ending with the residue $A$ exceeds the number of motifs ending with $T$. The finding suggests that BZLF1's ranked motif preference is TGWGCGA > TGWGCGT > TGWGYVA > TGWGYVT.

\section{Figure 4}

Changes in cellular chromatin accessibility after induction of EBV's lytic cycle by BZLF1.

(A) The metaplot summarizes the chromatin accessibility at the 145,000 BZLF1 binding sites

(Fig. 2) prior to and after induction of full-length or AD-truncated BZLF1 in Raji cell chromatin. The average ATAC-seq coverages in the four different Raji cell samples are plotted according to the nucleotide coordinates of the centers of the 145,000 BZLF1 peaks. In noninduced Raji iBZLF1 cells (BZLF1 full-length, low) the average ATAC-seq coverage is congruent with the coverage found in induced and non-induced Raji cells that carry the conditional AD-truncated BZLF1 allele. At induced BZLF1 levels (full-length, high) the average ATAC-seq coverage is substantially increased indicating a gain in chromatin accessibility. The inset provides the ATAC-seq coverage of 1,145,000 randomly sampled sequences in the chromatin of Raji iBZLF1 cells expressing full-length BZLF1 at high levels after doxycycline-mediated induction.

(B) The metaplot summarizes the ATAC-seq coverage at the 81,000 called peaks of open host chromatin identified prior to the induction of EBV's lytic phase. After induced expression of full-length BZLF1 the chromatin accessibility is strongly reduced indicating that open host chromatin becomes globally inaccessible upon induction of EBV's lytic phase. The ATACseq coverage is barely affected compared with non-induced cells when the AD-truncated BZLF1 protein is expressed. The data summarize three independent biological replicates.

\section{Figure 5}


Gene regulation in Raji cells upon doxycycline-induced expression of full-length BZLF1 compared with a BZLF1 variant lacking its transcriptional activation domain.

Three different cell lines (parental Raji cells [panel A], Raji iBZLF1 AD-truncated [panel B], and Raji iBZLF1 [panel C]) were induced with doxycycline for 6 hours and compared with their non-induced counterparts. The analyses are based on the hg19 reference genome and three replicates of each condition and cell line. Viral genes and NGFR (used as a doxycycline-regulated reporter gene) were excluded from the analyses.

(A) The transcriptomes of parental Raji cells were analyzed by comparing their untreated versus doxycycline treated ( 6 hours) states. No gene with more than 20 sequencing reads (vertical purple line) was found to be up- $(>2.5 \mathrm{x})$ or down-regulated $(<0.4 \mathrm{x})$ in the MA plots (upper and lower green horizontal lines, respectively). The median is centered at zero in the violin plot (lower panel). The distance between the quantiles that encompass $95 \%$ of all data points describes the spread of the gene populations which was determined to be $2^{0.28}$.

(B) RNA expression in Raji cells with a conditional activation-domain (AD)-truncated BZLF1 allele upon doxycycline induction for 6 hours. No gene was considered up- or downregulated. The violin plot reveals the very narrow spread of the gene population $\left(2^{0.42}\right)$ comparable to the results shown in panel $A$.

(C) RNA expression in Raji cells upon doxycycline induction of full-length wild-type BZLF1 (iBZLF1) after data normalization according to ERCC spike-in RNA reads. The MA plot shows a strong global reduction of cellular mRNA transcripts 6 hours after induction of BZLF1. 91 genes were upregulated (upper horizontal green line), while transcripts of 7,174 genes were reduced by a factor of at least 0.4 (lower horizontal green line). The MA violin plot shows that the median of the gene population is reduced by a factor of almost three ( 2 ${ }^{1.56}$ ) indicating a global reduction of mRNA steady state levels. The distance between the 2.5 and 97.5 quantiles shows a spread of the gene population of $2^{3}$.

\section{Figure 6}

Regulated genes and their association with BZLF1 ChIP-seq peaks and binding motifs in promoter regions.

(A) The numbers of ChIP-seq defined peaks are plotted on the $x$-axis versus the magnitude of gene regulation expressed as 'log2 fold change' on the $y$-axis after doxycycline induced expression of full-length BZLF1 in Raji iBZLF1 cells. The analysis includes the promoter proximal region $-5 \mathrm{~kb} /+1 \mathrm{~kb}$ of the transcriptional start sites (TSS) as indicated in the cartoon below. Forty-one genes without BZLF1 peaks within their defined promoter region were upregulated whereas about 4,500 gene were downregulated (upper and lower green lines, respectively). Fifty and about 2,600 genes that had BZLF1 peaks in their promoters were found to be up- or downregulated, respectively. 
(B) The number of BZLF1 motifs as defined in panel C of Figure 2 and Supplementary Figure S4 panel $C$ are plotted on the $x$-axis versus the magnitude of gene regulation on the $y$-axis as in panel A. BZLF1 motifs downstream and upstream of the TSS entered the analysis. The distribution of regulated genes ( $y$-axis) with or without BZLF1 binding sites follows the scheme in panel A. Below, the cartoon depicts one peak upstream and downstream of TSS with three and one BZLF1 motifs, respectively, illustrating the basics of this analysis and the location of the motifs.

\section{Figure 7}

\section{Gain and loss of chromatin interactions in Capture-C experiments 6 and 15 hours after induction of EBV's lytic cycle.}

The two MA plots summarize the dynamics of interactions between the promoter regions of 53 analyzed genes and their captured distal Dpnll fragments. The x-axis shows the number of identified interactions in log2 scale, the $y$-axis shows the log2 fold change between the paired time points.

(A1) After induction of the lytic cycle for six hours a slight global increase of the about 21,000 chromatin interactions is visible. Only fragments with more than 4 interactions were taken into consideration (vertical orange line). About 1,000 interactions showed a more than twofold increase (upper green horizontal line), while about 300 interactions were reduced by at least half (lower green horizontal line).

(A2) The violin plot summarizes $A 1$ and shows median and population spread.

(B1) After 15 hours of doxycycline-induced BZLF1 expression almost 4,000 fragments lose more than half of their interactions (lower green horizontal line) compared with the status prior to induction of the lytic phase. Conversely, 74 Dpnll fragments show a more than twofold increase of interactions (upper green horizontal line). In total only about 17,000 reach or exceed the threshold of 4 interactions.

(B2) In comparison with panel A2 the violin plot shows a clear reduction of the median and a slight increase of the population spread.

\section{Figure 8}

Loss of chromatin interactions between the MYC locus and the heavy chain enhancer. On the x-axis, individual chromatin interactions are shown as thin vertical lines of different heights that indicate their interaction frequencies (plotted on the $y$-axis as "number of interactions") with the MYC promoter region (approximate $-5 /+5 \mathrm{~kb}$ of the TSS). The promoter region is depicted as a green bar in the center of the plot, a grey arrow head points in the direction of transcription, and the light blue line at position "1" indicates the TSS. Grey vertical lines indicate the chromatin interactions prior to BZLF1 induction $(0 \mathrm{~h})$, orange and 
blue lines enumerate interactions 6 and 15 hours after adding doxycycline, respectively. The bottom part of the graph shows the positions of BZLF1 binding sites prior to (big, pink dots) and 15 hours after adding doxycycline (small, green dots). The $\mathrm{x}$-axis indicates the relative nucleotide coordinates (hg19 genome reference) encompassing two flanking regions $400 \mathrm{~kb}$ up- and downstream of the TSS. Due to a chromosomal translocation (vertical dashed red line), the heavy chain enhancer (HCE) on chromosome 14 drives the expression of the MYC locus on chromosome 8 in Raji cells. Prior to induction of BZLF1, the HCE (A and B) makes frequent contacts (grey vertical lines) with the MYC locus. Chromatin interactions decrease after $6 \mathrm{~h}$ (orange lines) and are further reduced to about $20 \%$ (blue lines) $15 \mathrm{~h}$ after BZLF1 induction. Both HCE interacting $A$ and $B$ loci colocalize with numerous BZLF1 ChIP-seq peaks. In Raji cells, $6 \mathrm{~h}$ after BZLF1 induction the level of $M Y C$ transcripts is reduced to $2 \%$ compared with the non-induced state. 


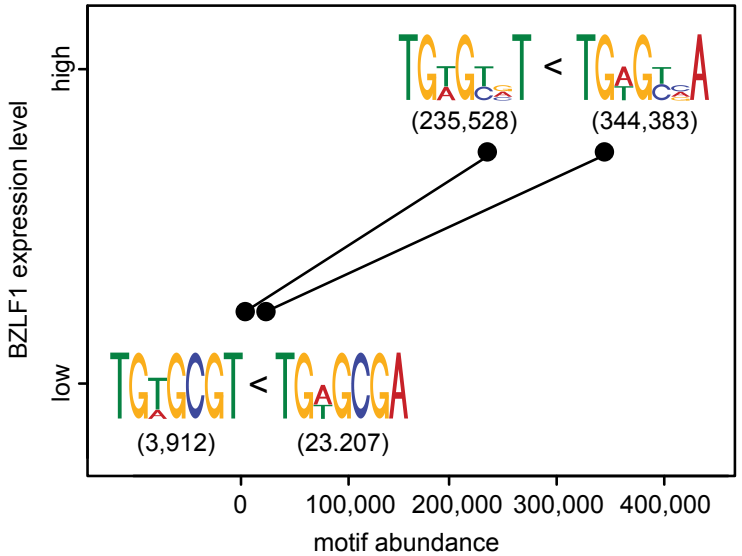



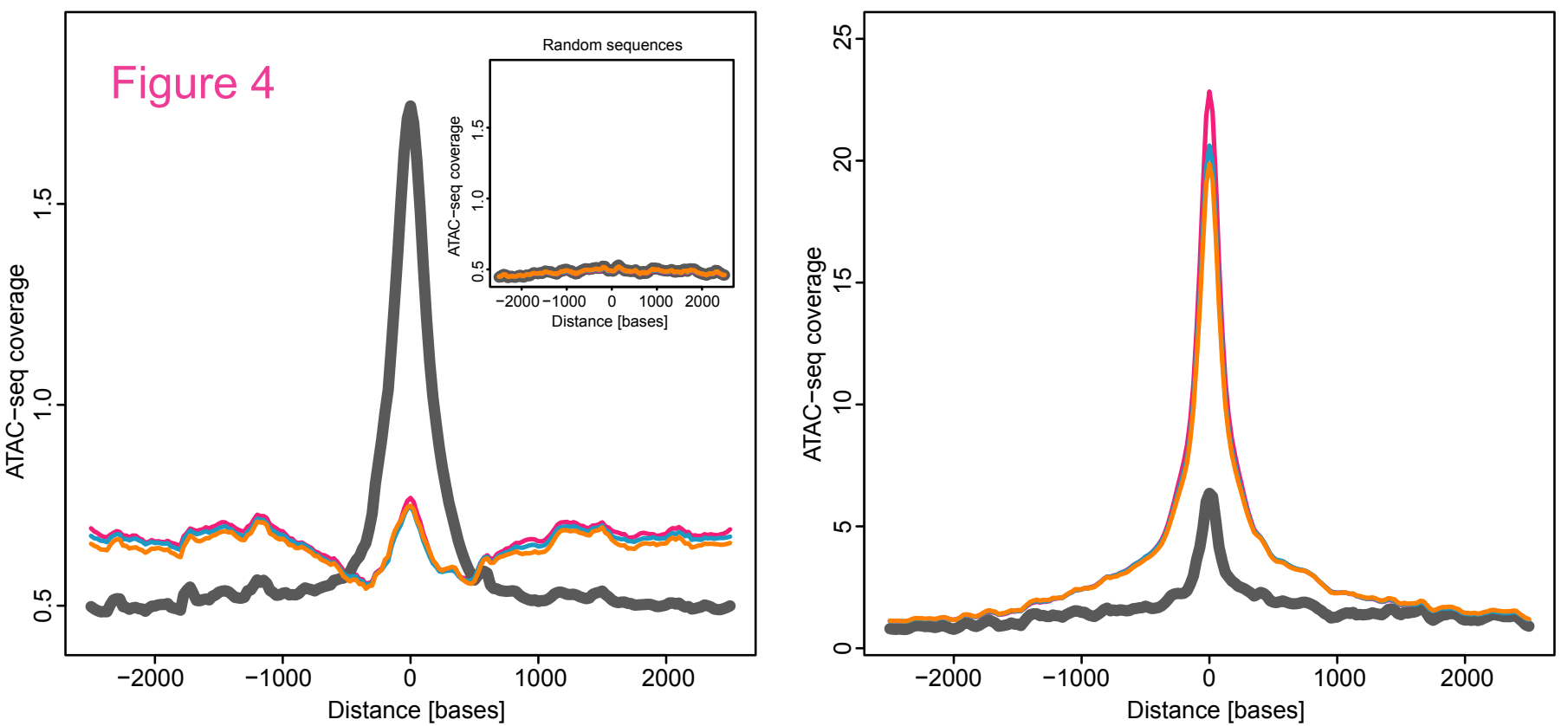
A

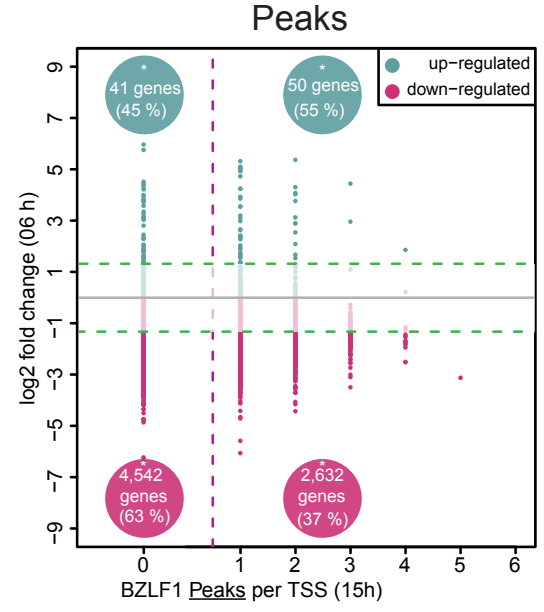

I B

, B

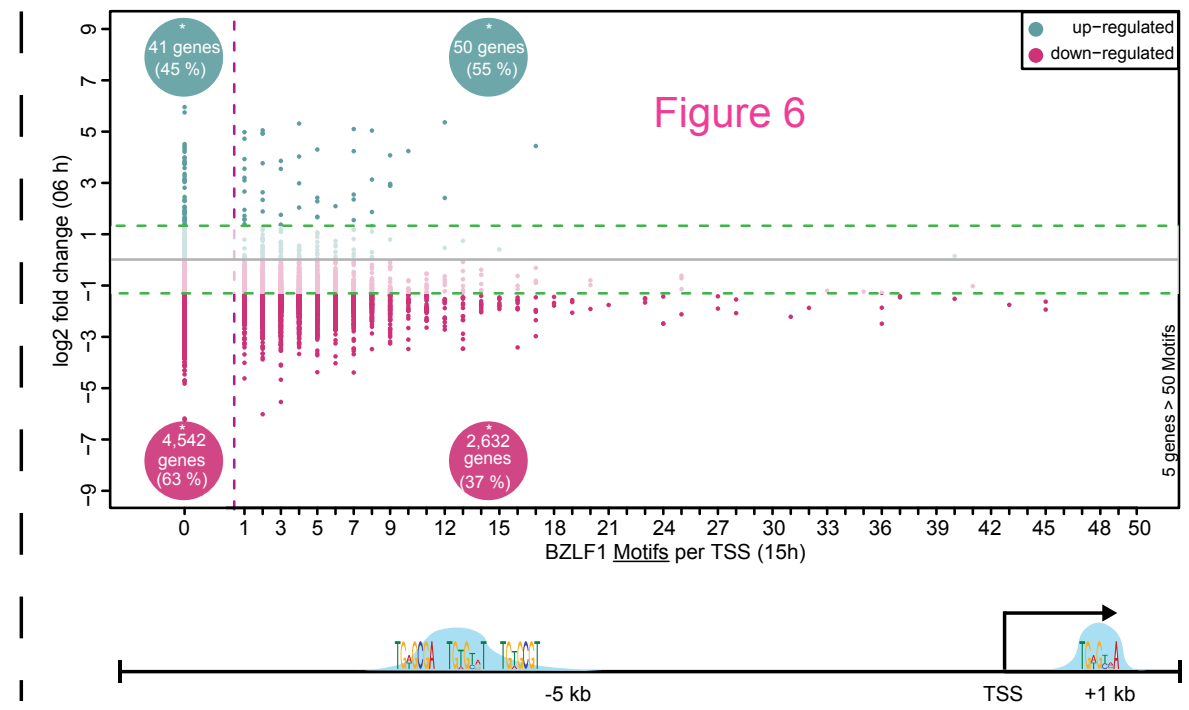

\section{Motifs}

Figure 6

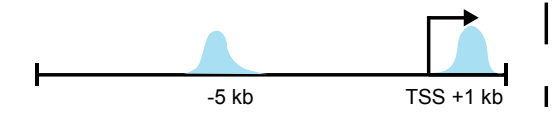


Raji iBZLF1 0 vs $6 \mathrm{~h}$

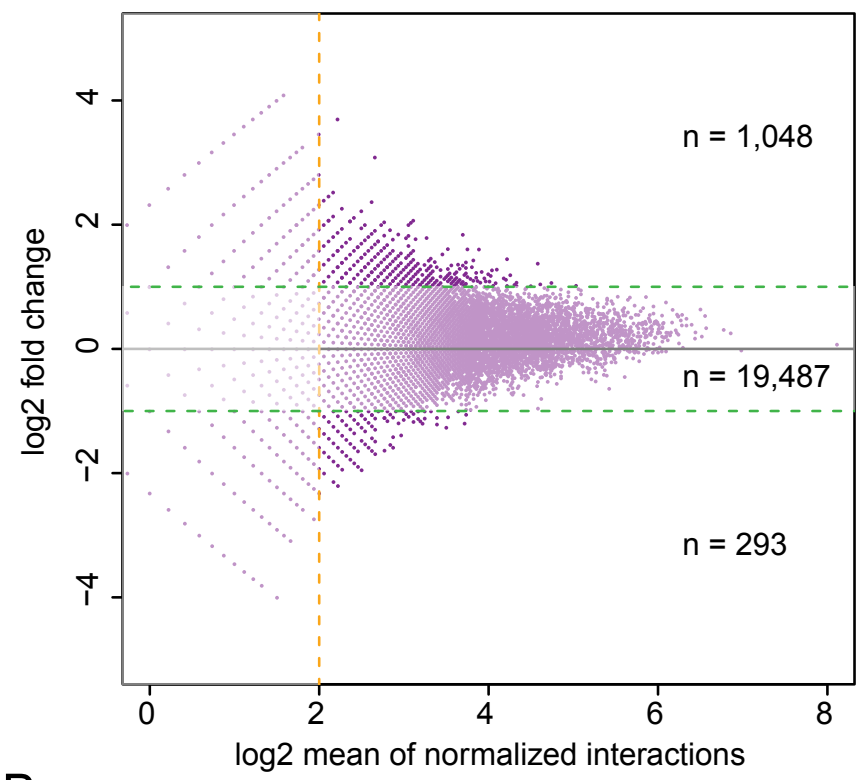

$\mathrm{B}_{1}$

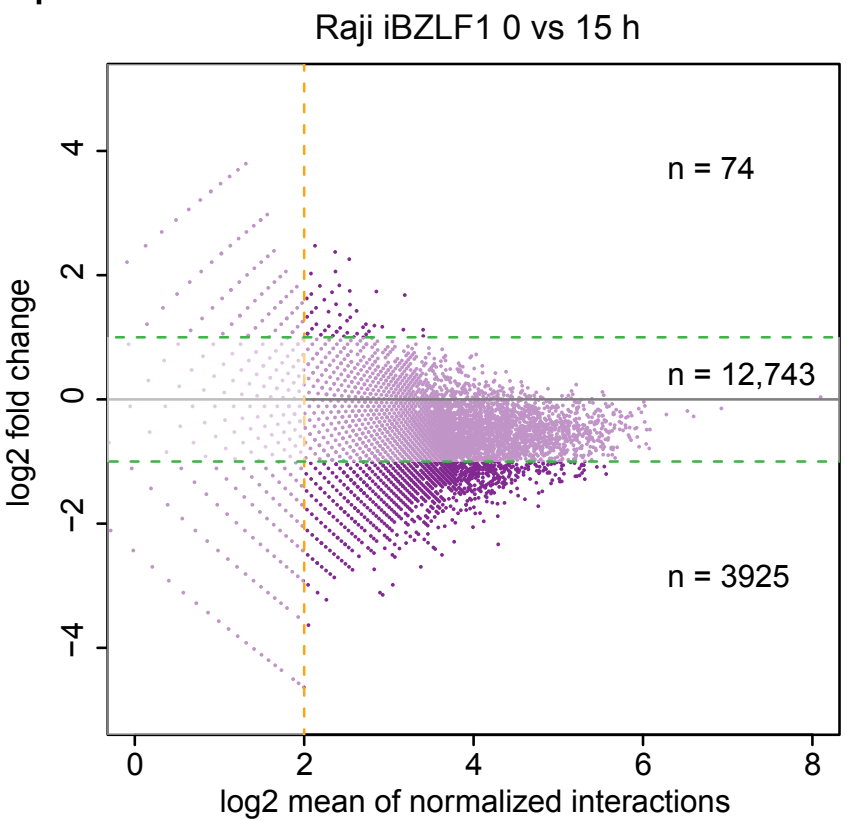

Raji iBZLF1 0 vs $6 \mathrm{~h}$

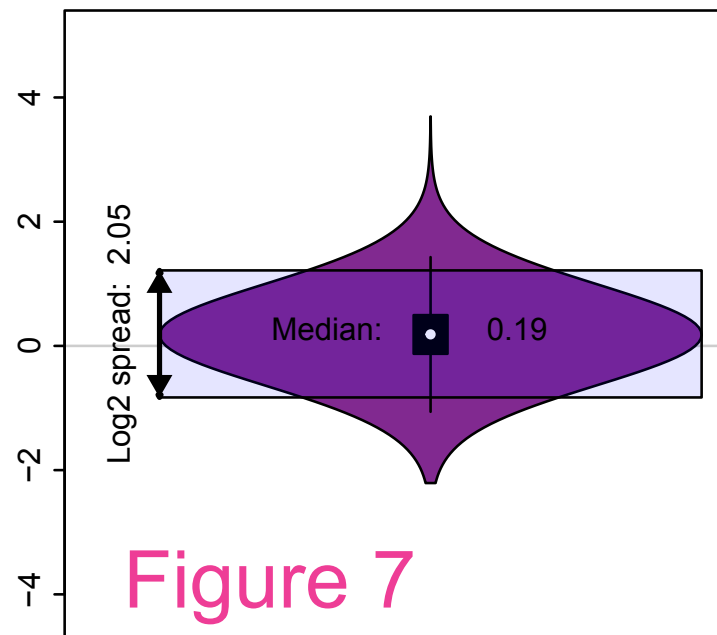

Interactions: 20,828

$\mathrm{B}_{2}$

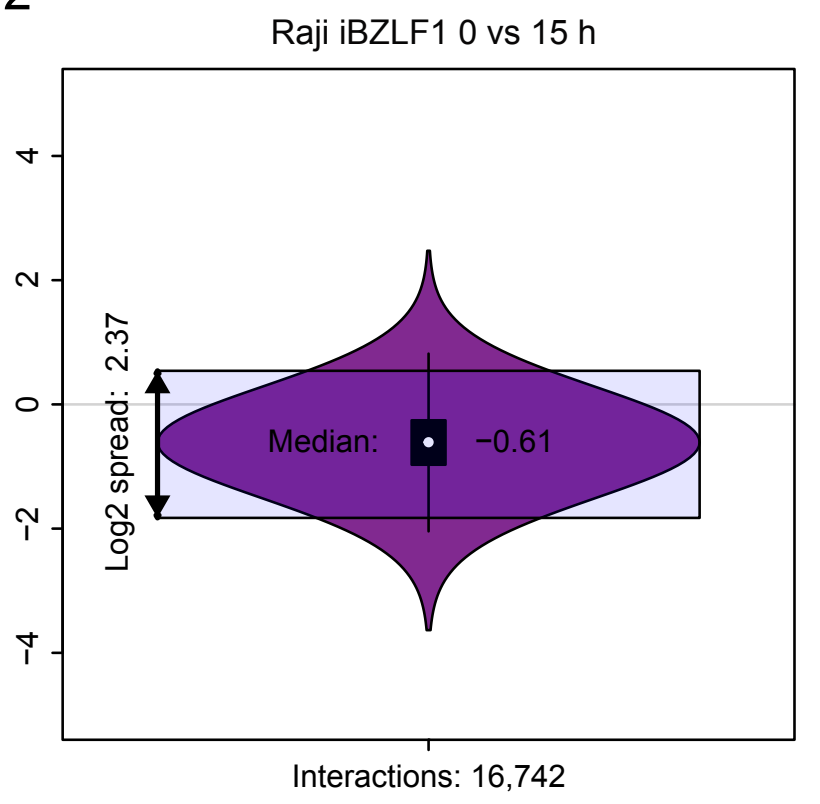




\section{- BZLF1 ChIP low \\ - BZLF1 ChIP high}

$0 \mathrm{~h}$ interactions

$6 \mathrm{~h}$ interactions $15 \mathrm{~h}$ interactions

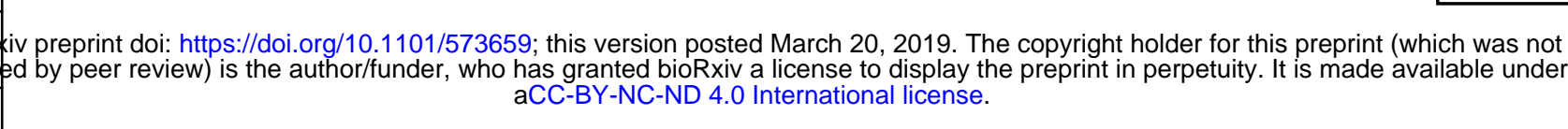

$$
\text { , }
$$

\section{Figure 8}

MYC information box down-regulated: 0.02 TSS: \# 128,748,314 direction of transcription Capture-C probe

- - Translocation breakpoint

(B)

(A) 